\title{
Progenitor cell integration into a barrier epithelium during adult organ turnover
}

\author{
Paola Moreno-Roman ${ }^{1,+}, \mathrm{Yu}-\mathrm{Han} \mathrm{Su}^{1}$, Anthony Galenza ${ }^{1}$, Lehi Acosta ${ }^{1}$, Alain Debec ${ }^{2 \S}$, \\ Antoine Guichet ${ }^{2}$, Jon-Michael Knapp ${ }^{3}$, Caroline Kizilyaprak ${ }^{4}$, \\ Bruno M. Humbel ${ }^{4,5, \neq}$, Irina Kolotuev ${ }^{4}$, \& Lucy Erin O'Brien ${ }^{1^{*}}$
}

\section{Affiliations:}

${ }^{1}$ Department of Molecular \& Cellular Physiology, Stanford School of Medicine, Stanford, CA 94305 USA

${ }^{2}$ Equipe Polarité et Morphogenèse, Institut Jacques Monod, CNRS-Université de Paris, 75205 Paris CEDEX 13 - France

${ }^{3}$ Luminint Consulting Group, LLC.

${ }^{4}$ Universite de Lausanne, Bâtiment Biophore, Quartier Sorge, CH-1015 Lausanne, Switzerland

${ }^{5}$ Department of Cell Biology and Neuroscience, Juntendo University Graduate School of Medicine, Tokyo 113-8421, Japan

${ }^{\dagger}$ Present address: Foldscope Instruments, Inc.

^Present address: IMG, Okinawa Institute of Science and Technology, Tancha, Okinawa, Japan

SPresent address: Institute of Ecology and Environmental Sciences, iEES, Sorbonne University, UPEC, CNRS, IRD, INRA, F-75005 Paris, France

*Corresponding author: lucye@stanford.edu 


\section{ABSTRACT}

Barrier epithelial organs face the constant challenge of sealing the interior body from the external environment while simultaneously replacing the cells that contact this environment. These replacement cells— the progeny of basal stem cells—are born without apical, barrier-forming structures such as a protective, lumen-facing membrane and occluding junctions. How stem cell progeny acquire these structures to become part of the barrier is unknown. Here we use Focused Ion Beam-Scanning Electron Microscopy (FIB-SEM), Correlative Light-Electron Microscopy (CLEM), and volumetric imaging of live and fixed organs to investigate progenitor integration in the intestinal epithelium of adult Drosophila. We find that stem cell daughters gestate their future lumenal-apical membrane beneath a transient, basal niche formed by an umbrella-shaped occluding junction that shelters the growing cell and adheres it to mature neighbor cells. The umbrella junction both targets formation of a deep, microvilli-lined, apical invagination and closes it off from the contents of the gut lumen. When the growing cell is sufficiently mature, the umbrella junction retracts to expose this Pre-Assembled Apical Compartment (PAAC) to the gut lumen, thus incorporating the new cell into the intestinal barrier. When we block umbrella junctions, stem cell daughters grow and attempt to differentiate but fail to integrate; when we block cell growth, no umbrella junctions form, and daughters arrest in early differentiation. Thus, stem cell progeny build new barrier structures in the shelter of a transient niche, where they are protected from lumenal insults until they are prepared to withstand them. By coordinating this dynamic junctional niche with progenitor cell differentiation, a physiologically active epithelial organ incorporates new cells while upholding integrity of its barrier.

\section{INTRODUCTION}

Barrier epithelial organs protect the body interior from the external environment while performing physiological processes that require direct exposure to this environment. For example, the epithelium of the digestive tract both protects the body from gastric acid and enteric pathogens while simultaneously breaking down and absorbing ingested nutrients. The dual roles of barrier epithelia create a conundrum: Optimal physiological function requires that the tissue replace old, spent cells with new stem cell progeny, but each individual progeny must be incorporated into the epithelium without compromising barrier integrity (Guillot and Lecuit, 2013; Leblond, 1981; Liang et al., 2017; Macara et al., 2014; Pellettieri and Alvarado, 2007). The cellular mechanisms which enable stem cell progeny to seamlessly assimilate into a functioning barrier are poorly understood. 
In all metazoans, epithelial barrier function arises from two conserved features of the epithelial cells themselves. First, cell-cell occluding junctions-tight junctions in vertebrates, septate junctions in invertebrates_create impermeable seals between cells (Varadarajan et al., 2019). Occluding junctions encircle each epithelial cell at the lateral border of the apical membrane, creating a sealed network that prevents even small molecules from freely passing between the lumen and the body interior. Second, a lumen-facing, apical plasma membrane, tightly folded into microvilli or cilia, forms a mucosal shield that resists corrosives, pathogens, and other lumenal insults (Linden et al., 2008; McGuckin et al., 2011; Overeem et al., 2015). This apical membrane is a hallmark of epithelial differentiation and serves as the barrier's direct interface with the outside world. In contrast, the stem cells that renew many barrier epithelia lack occluding junctions and a lumen-contacting apical membrane. Examples of such epithelia include the mammalian trachea (Evans and Moller, 1991; Michael J. Evans, 2001; Rock et al., 2009; Sekiya et al., 1988), mammary gland (Chepko and Dickson, 2003; Chepko and Smith, 1997), prostate (Tsujimura et al., 2002), cornea (Cotsarelis et al., 1989), and olfactory lining (Leung et al., 2007), and the Drosophila adult midgut (Korzelius et al., 2014; Resnik-Docampo et al., 2017; Xu et al., 2019). Stem cells in these tissues are much smaller than their mature progeny; they inhabit the basal region of the epithelium, protected from lumenal contents by the mature cells' occluding junction network.

Since stem cells lack barrier-forming structures, their progeny must generate these structures de novo as they integrate into the barrier during terminal differentiation. Radial intercalation has been proposed to be this integration mechanism (Walck-Shannon and Hardin, 2014; Sedzinski et al., 2016; Chen et al., 2018). Many developing epithelial tissues use radial intercalation to merge basally derived cells into an overlying epithelium (Merzdorf et al., 1998; Deblandre et al., 1999; Stubbs et al., 2006; Voiculescu et al., 2007; McMahon et al., 2008; Campbell et al., 2010). In this process, a cell that is born basal to the occluding junction network integrates into this network by moving apically while wedging itself between pre-existing cells. When the tip of the intercalating cell reaches the epithelium's occluding junctions, the new cell forms occluding junctions with its neighbors. These SJs begin as a pinpoint and morph into a ring that surrounds the cell's nascent, lumen-facing apical membrane. This apical membrane and its encircling occluding junction expand radially as the cell grows to its final size (Stubbs et al., 2006; Sedzinski et al., 2016, 2017). Like these developmental contexts, integration of adult stem cell progeny involves basal-to-apical movement and de novo formation of barrier-forming structures. Whether stem cell progeny use radial intercalation or an alternate, perhaps novel, mechanism, remains unexamined.

We leveraged recent advances in Focused Ion Beam-Scanning Electron Microscopy (FIBSEM), Correlative Light-Electron Microscopy (CLEM - (Burel et al., 2018)), and in vivo volumetric confocal live imaging (Martin et al., 2018) to directly examine this question using the midgut of adult Drosophila. Like many vertebrate barrier epithelia, the epithelial lining of the fly midgut is a leakproof, pseudostratified epithelium that is continually renewed through the divisions of basal stem cells (Lemaitre and Miguel-Aliaga, 2013). Investigating how new stem cell progeny assimilate 
into this adult barrier epithelium, we found-unexpectedly—that assimilation occurs not by radial intercalation but by a striking morphogenetic process that has not previously been described for any tissue.

We discovered that as a stem cell daughter undergoes terminal differentiation, its nascent occluding junctions form a transient, umbrella-shaped niche that supports development of the cell's future, lumen-facing apical surface. This surface starts as an intercellular, localized delamination within the umbrella-shaped junction. The delaminated membrane of the differentiating cell accumulates apical markers, invaginates deeply into the cell's cytoplasm, and folds into microvilli in the shelter of the junctional niche; these behaviors create a pre-âssembled apical compartment (PAAC) on the basal side of the epithelial barrier, protected from the contents of the gut lumen. In the final phase of cell differentiation, the umbrella junction retracts to fuse the PAAC with the gut lumen, and the apical membrane everts to form the mature cell's convex lumenal surface.

The morphogenetic process of progenitor cell integration is coupled to growth that progenitor cells undergo as they terminally differentiate. When we block stem cell daughters from integrating, they become trapped in a hybrid, partially differentiated state and accumulate on the basal side of the epithelium. These animals die prematurely, implying that organismal longevity is compromised when the intestinal barrier is not properly replenished.

We suggest that PAAC-mediated integration enables stem cell progeny to generate lumenfacing cell surfaces in a space that is protected from lumenal insults, thus enabling new cells to be added seamlessly to a physiologically active barrier epithelium.

\section{RESULTS}

Mature intestinal enterocytes form the bulk of the Drosophila midgut and are responsible for its barrier function. Like their vertebrate counterparts, Drosophila enterocytes are bonded together by apical occluding junctions (Figs. 1A \& 2A). In the fly gut, these occluding junctions are smooth septate junctions (SJs) (Furuse and Izumi, 2017). Also like their vertebrate counterparts, Drosophila enterocytes display an apical brush border composed of long, dense microvilli (Fig. 2A); the brush border both absorbs nutrients and protects against lumenal pathogens.

Enterocytes are terminally differentiated and post-mitotic. When shed through damage or death, they are replaced by division of resident stem cells (Micchelli and Perrimon, 2006; Ohlstein and Spradling, 2006; Jiang and Edgar, 2009; Liang et al., 2017). Stem cell progeny that are fated to become enterocytes must first pass through an intermediate, post-mitotic stage called an enteroblast (Ohlstein and Spradling, 2007; Bardin et al., 2010; Perdigoto et al., 2011) (Figure 1A). Enteroblast identity is determined by activation of the Notch receptor and can be visualized using Notch reporters such as $S u(H)$-GFP::nls and $S u(H)$-lacZ (Ohlstein and Spradling, 2007; Bardin et al., 2010; Perdigoto et al., 2011; de Navascués et al., 2012). As enteroblasts differentiate to enterocytes, they endoreplicate from $2 \mathrm{~N}$ to $32-64 \mathrm{~N}$ and increase in volume by $\sim 30 \mathrm{x}$ (Xiang et al., 2017). 


\section{Stem cell progeny initiate new SJs at discrete contact points with mature cells}

We were intrigued by prior observations that stem cells lack SJs (Korzelius et al., 2014; Resnik-Docampo et al., 2017; Xu et al., 2019) because this implies that differentiating cells must form SJs de novo and integrate themselves into the enterocytes' leakproof SJ network. We sought to determine when, where, and how de novo SJ formation occurs. First, we asked whether enteroblasts form SJs with their mature enterocyte neighbors (Figs. 1 \& 2). If so, then SJ components should localize to enteroblast-enterocyte interfaces. To investigate this prediction, we used midguts that expressed markers to distinguish enteroblasts, enterocytes, and stem cells. We immunostained them for the SJ components Snakeskin (Ssk) and Tetraspanin2A (Tsp2A) (Yanagihashi et al., 2012; Izumi et al., 2016), then performed 5-channel multi-photon laser scanning microscopy to visualize SJs in the context of identified cells.

We observed SJ components at nearly all enteroblast-enterocyte interfaces, but not at the vast majority of stem cell-enterocyte interfaces nor at any stem cell-enteroblast interfaces. $89 \%$ of stem cells (escargotGAL4, UAS-his2b::CFP (esg $\left.{ }^{+}\right)$, Armadillo $\left(\mathrm{Arm}^{+}\right)$, Su(H)-GFP::nls-) exhibited no colocalization with SJ components ( $\mathrm{n}=119$ stem cells from 5 guts) (Fig. 1B \& 1E), as expected (Korzelius et al., 2014; Resnik-Docampo et al., 2017; Xu et al., 2019). By contrast, 92\% of enteroblasts (esg', Arm+, $\mathrm{Su}(\mathrm{H})$-GFP::nls ${ }^{+}$(Figs. 1C, 1D, 1F \& 1G) overlapped with enterocyte-enterocyte SJs (n=125 enteroblasts from 5 guts). Many SJ-contacting enteroblasts exhibited small, presumably diploid, nuclei, which suggests that these contacts are formed in initial stages of enteroblast fate determination.

Enteroblast SJ staining invariably localized to the apical-most tips (apex) of the enteroblasts, where it overlapped with the basal terminus of the enterocyte SJs. This overlap might represent either bona fide adhesion septa between enteroblasts and enterocytes or else the mere physical proximity without formation of true adhesion septa. To distinguish these scenarios, we performed correlative light-electron microscopy (CLEM) (Kolotuev, 2014) on Su(H)-GFP::nls-expressing midguts to identify the GFP-labelled enteroblasts. FIB was performed in random positions of the midgut R4c region; GFP-labeled enteroblasts were identified; and interfaces between these enteroblasts and neighbor enterocytes were examined for potential SJ septa.

In EM, SJ septa characteristically appear as electron-dense structures that 'fuse' together the apposing plasma membranes of adjacent cells. As expected, enterocyte-enterocyte septa fused together the apical-most regions of the cells' lateral membranes, directly adjacent to their microvillirich brush borders (Fig. 2A). However, when enterocytes were next to an enteroblast (Figs. 2B-2E), their SJs extended basally toward the enteroblast (red pseudocolor in Fig. 2B") and fused with enteroblast plasma membrane at its apex (arrowheads). These observations demonstrate that enteroblasts form bona fide SJ septa with mature neighbor cells. In addition, they imply that lightmicroscopy visualized overlap of immunostained SJ components with enteroblast cell membranes (Fig. 1) are sites of new SJ formation. 
To understand the three-dimensional structure of enteroblast-enterocyte SJs, we performed array tomography. We transformed the tomograms into volumetric renderings of individual cells and their SJ interfaces. Fig. 2C and Video 1 show the volumetric rendering of a 30-slice series surrounding the CLEM image in Fig. 2B. The apex of this diploid (presumably, newly determined) enteroblast (red) exhibits three finger-like projections (arrowheads), each of which forms a pointlike, discrete SJ (green) with one of its three neighbor enterocytes (blue; labelled 1-3 in Fig. 2B). No SJs are visible between the enteroblast and an adjacent, $\mathrm{Su}(\mathrm{H})$-GFP::nls-negative stem cell (yellow). The enteroblast's three point-like SJs contact the three enterocyte SJs (pink, pale blue, and purple) at the latters' basal rim. Importantly, we found no discontinuities between the new, enteroblastenterocyte SJs (overlap between green and either pink, pale blue, or purple) and the pre-existing, enterocyte-enterocyte SJs (overlap between pink and pale blue, pink and purple, or pale blue and purple). This structural continuity suggests that the pre-existing, enterocyte-enterocyte SJ guides the localization of initial SJ contacts between enterocytes and the new enteroblast.

\section{SJ contacts develop into a large, umbrella shaped SJ that covers the enteroblast apex and extends toward the basal epithelium}

We next generated a volumetric rendering of a larger (hence, likely older) enteroblast (red) from a 413-slice FIB-SEM tomographic series that spanned a $35.6 \mu \mathrm{m} \times 35.6 \mu \mathrm{m} \times 4.5 \mu \mathrm{m}$ tissue volume. A single slice from this series is shown in Figs. 2D-D" and Fig. S1, and the volumetric rendering is shown in Figure 2E and Video 2. In contrast to the nascent SJ contacts formed by a young enteroblast (Figures 2B \& 2C), the SJ (green) of this older enteroblast is an expansive, adhesive 'zone' whose shape resembles an umbrella. This umbrella SJ fuses the pyramidal enteroblast to three mature neighbor cells: the SJs (pink and purple) of two enterocytes (blue; labelled 1 and 2 in Figs. 2D \& 2E) and those of an enteroendocrine cell (pale blue; labelled 3 in Fig. 2D). No SJs are visible at the interface between the enteroblast and a presumptive stem cell (yellow). As with SJs of the young enteroblast (Fig. 2B-C), the SJs between the older enteroblast and its neighbor enterocytes (green/pink overlap and green/purple overlap) are continuous with the SJ that had previously formed between the enterocytes themselves (pink/ purple overlap).

Importantly, the umbrella SJ extends unusually far toward the basal epithelium-a feature that is incompatible with a simple model of radial intercalation. SJs typically occupy a narrow band at the apical border of the enterocytes' lateral membranes (Fig. 2A; also in Fig. 2E and E', the purple SJ on left side of enterocyte 1 and pink SJ on right side of enterocyte 2). In radial intercalation, the SJ initiates at the point where the new cell's apical tip becomes co-planar with the organ's mature SJ network; hence, the new SJ grows to a narrow width that matches that of mature SJs (WalckShannon and Hardin, 2014; Stubbs et al., 2006; Sedzinski et al., 2016, 2017; Chen et al., 2018). However, an enteroblast's umbrella SJ spreads basally along two-thirds of the enterocytes' lateral membranes and shrouds the top third of the enteroblast (Fig. 2E, green SJ and associated pink and 
purple SJs; Video 2). This basally extended umbrella shape implies an alternate mode of integration in which the new SJ forms basal to the organ's mature SJ network.

\section{Cloning Meduse, an actin-associated protein that localizes to the brush border of midgut enterocytes}

The second component of the gut's barrier structure is collectively formed by the apical cell surfaces that line the gut lumen. Mature enterocytes fold these surfaces into long, dense microvilli, forming the intestinal brush border (Fig. 2A). Mature enterocytes also exhibit apical-basal polarity, as characterized by lumen-polarized localization of cytoskeleton-associated proteins such as Moesin, Karst ( $\beta_{\mathrm{H}}$-spectrin), and Myosin7a (Baumann, 2001; Chen et al., 2018).

Another luminally polarized marker is provided by the splice-trap transposon line A142 (Bobinnec et al., 2003; Buchon et al., 2013), which expresses a GFP fusion protein that co-localizes with Moesin at or near enterocyte microvilli (Fig. 3A-C). We found that this transposon is inserted into CG2556 (Fig. S2A), a previously uncharacterized gene that does not appear to have vertebrate homologs. Since the filamentous appearance of the A142 fusion protein in egg chambers is reminiscent of sea jelly tentacles (Fig. S2B), we named this gene Meduse (Mdu). Meduse is predicted to be a 470 amino-acid, $51 \mathrm{kDa}$ protein whose sole identifiable motif is an actin binding domain. This putative actin-binding function is consistent with localization of the A142 splice trap to the apical brush border of enterocytes and with actin filaments in Stage 10 egg chambers, the latter of which is latrunculin-sensitive (Fig. S2B-C).

\section{The umbrella SJ is a transient niche for formation of the new cell's future lumenal-apical surface}

During development of tubular epithelial organs, cells generally couple the formation of a lumen-contacting cell surface to the formation of apical features including microvilli, occluding junctions, and apically polarized membrane and cytoskeletal proteins (Blasky et al., 2015; Datta et al., 2011; O'Brien et al., 2002; Sigurbjörnsdóttir et al., 2014). By comparison, stem cells in the adult fly gut lack this entire suite of lumenal-apical features (Figs. 2B-2E) (Chen et al., 2018). How do stem cell progeny generate a lumenal-apical surface as they differentiate, and how do they coordinate apical morphogenesis with SJ formation and epithelial integration?

To address this question, we used high-resolution images of fixed guts to identify cells at distinct stages of differentiation, assessed the localization of apical markers, and correlated apical marker localization to SJ maturation (Figs. 3 \& S2 and Video 3). Midguts that express Su(H)-lacZ were used because the long perdurance of $\beta$-galactosidase ( $>20 \mathrm{~h}$ half-life (Bachmair et al., 1986)) makes it possible to identify early-stage enterocytes that have recently turned off enteroblast-specific $\mathrm{Su}(\mathrm{H})$ activity but have not yet completed terminal morphogenesis (Fig. S3). Comparing apical 
marker localization, SJ morphology, and the cytoplasmic and nuclear sizes of $\mathrm{Su}(\mathrm{H})$-lacZ ${ }^{+}$cells, we distinguished four stages of apical membrane morphogenesis.

In Stage 1 (left-most column in Fig. 3), enteroblasts are small, and their nuclei appear diploid; this stem-like appearance is consistent with the cells being in early stages of terminal differentiation. Stage 1 enteroblasts lack apical polarity, but they have formed SJ contacts with enterocytes. The few apical markers that are expressed, such as Moesin (Figs. 3A and C), do not show a polarized distribution; other apical markers, such as Karst and Meduse (Figs. 3B and 3C), are not detectable. The apex of Stage 1 enteroblasts contacts the basal terminus of enterocyte-enterocyte SJs, as revealed by localization of SJ components Tsp2A and Ssk (Figs. 3A and 3C). We interpret these SJ contacts to be nascent, point-like SJs, like those formed by the enteroblast in Figs. 2B and 2C.

In Stage 2 (Fig 3, second column from left), enteroblasts preferentially localize apical markers to their apex; this enrichment forms a bright plaque that is covered by broadened SJ contacts (Figs. $3 \mathrm{~A}-\mathrm{C})$. We suggest that this apical plaque represents early stages of polarization since low levels of apical markers persist at other cortical regions. The enteroblast SJ grows to cover the cell's entire apex; we infer that these Stage 2 SJs are like the SJ in Figs. 2D and 2E. With respect to morphology, some Stage 2 enteroblasts (e.g. Figs. 3B and 3C) are similar in cytoplasmic and nuclear size to Stage 1 enteroblasts; other Stage 2 enteroblasts are slightly larger, and their nuclei appear intermediate in ploidy between $2 \mathrm{~N}$ stem cells and 32-64N, mature enterocytes (e.g. Fig. 3A).

In Stage 3 (Fig. 3, third column from left), the differentiating cells resemble immature enterocytes. Their cytoplasmic and nuclear volumes are larger than Stage 1-2 enteroblasts, yet smaller than mature enterocytes, and their low levels of $\beta$-galactosidase suggest that $\mathrm{Su}(\mathrm{H})$ enhancer activity was diminishing. We refer to these cells as pre-enterocytes. Apical markers-now highly expressed-localize to a conspicuous, concave structure that is covered by the broad, umbrellashaped SJ sheet that we described above. These concave structures are the morphological hallmarks of Stage 3. With diameters up to $12 \mu \mathrm{m}$-roughly the diameter of a mature enterocyte-they often fill the apex of the pre-enterocytes. We were surprised to discover that they are topologically discontinuous with the midgut lumen (Video 3), another feature that is incompatible with radial intercalation. Instead, we conjecture that these structures are precursors of the pre-enterocytes' future lumen-contacting surface. Hence, we designate them as Pre-Assembled Apical Compartments (PAACs).

In Stage 4, (Fig. 3, right column), pre-enterocytes finish integrating into the gut epithelium by acquiring a topology of cell-cell interfaces that is equivalent to mature enterocytes. Stage 4 cells are circumscribed (rather than covered as in previous stages) by SJs, and they now possess a lumencontacting apical surface. The shapes of Stage 4 lumen-contacting surfaces and Stage 3 PAACs are highly similar, which suggests that the PAAC opens to the gut lumen via remodeling of its overlying umbrella SJ into a ring. Stage 4 cells are smaller in cytoplasmic volume and nuclear size compared to mature enterocytes. In a final Stage 5 (Fig. S3D), the cell acquires its mature size and 
ploidy and everts its lumenal-apical surface to form a convex shape, thus completing terminal differentiation.

Altogether, this morphogenetic sequence reveals that midgut stem cell progeny do not form new SJs and an apical membrane via radial intercalation into the epithelial barrier. Rather, they form these barrier structures while still in the basal epithelium, protected by the mature barrier.

\section{Live imaging of enteroblast-enterocyte integration}

We next asked whether live imaging corroborates the four-stage sequence (Fig. S3D) of enteroblast-enterocyte integration implied by fixed samples. To address this question, we performed continuous time-lapse imaging using Windowmount methodology, in which volumetric movies of physiologically functioning guts are captured in live animals through a window cut into the dorsal cuticle (Fig. 4A) (Martin et al., 2018). Prior analyses of stem cell clones in both fixed guts (He et al., 2019; de Navascués et al., 2012) and intravital live imaging (Koyama et al., 2020) suggest that most enteroblasts require $>24 \mathrm{~h}$ to differentiate into enterocytes. Although this time frame is longer than the 16-20 $\mathrm{h}$ viability of animals during Windowmount (Martin et al., 2018), longitudinal imaging suggests that some cells differentiate in $<24 \mathrm{~h}$ (Koyama et al., 2020). Therefore, we aspired to capture these faster cells.

We first examined live dynamics of SJs. From nine movies of GS5966>tsp2A::GFP; Su(H)$m$ Cherry midguts with durations from 7.25-20 h, we identified one movie in which an mCherryexpressing cell increased in cross-sectional area by nearly three-fold (Fig. 4B \& 4D, and Video 4); this dramatic growth is an identifying feature of enteroblast-enterocyte differentiation. To determine whether the Tsp2A::GFP-labelled SJ associated with this cell exhibited dynamics consistent with the mechanism implied by Fig. 3, we analyzed an orthogonal view through the cell's apical-basal axis (Fig. 4C). In the movie's initial $105 \mathrm{~min}$, the SJ that contacted the differentiating cell grew broader and ultimately covered the cell's entire apex (Fig. 4C, arrow in 0- and 90-min panels; Video 4, 0-105 $\mathrm{min})$. This broadening is consistent with the notion that SJs expand from discrete contact points in Stage 1 (Fig. 2C, Fig. 3A \& 3B, and Video 1) to an umbrella shape in Stages 2 and 3 (Fig. 2E, Video 2, Fig. 3A \& B, Fig. 5D, and Video 6). Between 120-285 min, a hollow space developed along the SJ's apical-basal axis; simultaneously, the SJ extended along the lateral faces of the now-larger cell (Fig. 4C, arrows (SJ) and asterisks (hollowing) in 195- and 285-min panels; Video 4, 120-285 min). This hollowing and lateral extension are consistent with remodeling of the $S J$ from an overlying sheet in Stage 3 to a circumscribing ring in Stage 4 (Fig. 3A \& 3B). Overall, these live SJ dynamics support the morphogenetic sequence suggested by the fixed analyses in Fig. 3.

We next examined live dynamics of the apical membrane using midguts that expressed the apical marker Moesin::GFP and the nuclear marker His2av::mRFP (Fig. 4E and Video 5). The Moesin::GFP-labelled lumenal-apical membranes appeared as a convoluted surface atop the gut cells' nuclei because the apical surface of mature enterocyte is domed (e.g. Fig. 2A). Basal to the 
lumenal-apical membranes, we frequently observed GFP-labelled structures that were fainter in intensity and concave in shape. We conjecture that these structures are PAACs. While most PAACs did not dramatically change in shape or size during imaging, some PAACs became brighter and deeper over time (e.g., Fig. 4E and Video 5). This evolution is consistent with Stages 3-4 of differentiation, during which PAACs initially form and subsequently become larger and more enriched for apical markers (Fig. 3, Stages 2-3). Overall, we conclude that live imaging of SJ and apical membrane dynamics provides additional support for the four-stage mechanism suggested by fixed tissues.

\section{PAACs are intercellular lumens formed by asymmetric pre-enterocyte apical membranes and enterocyte basolateral membranes}

Our finding that PAACs are physically distinct from the gut's lumenal-apical surface raises basic questions about the nature of these structures: Are they intracellular or intercellular? What is their relationship to the developing SJ? Does their apical polarity correspond to a mature brush border? To gain insight into these and other questions, we examined the PAACs' ultrastructure in FIB-SEM tomographic series.

To identify putative PAACs, we first identified pre-enterocytes by looking for polyploid cells that lacked a visible lumenal-apical surface. We noticed that the apexes of such pre-enterocytes frequently contained membrane-bound, ellipsoid ultrastructures (Fig. 5A-cyan box, and Fig. 5B) whose shape and cellular position resembled PAACs. These structures enclosed prominent lumens that are distinct from the gut lumen, circumscribed by SJs, and lined with microvilli. The microvilli are densely arrayed, like brush border microvilli, but they are shorter, which suggests they are immature. Notably, Moesin, which outlines PAACs in confocal micrographs (Fig. 3 and Video 3), is a marker of microvilli in other Drosophila epithelia (Edwards et al., 1997; Lattner et al., 2019). We also found sausage-shaped (allantoid) ultrastructures that, like the ellipsoids, are lined with dense microvilli and circumscribed by SJs (Fig. 5A-magenta box, and Fig. 5C). The allantoids' lumens are extremely slender, suggesting that they may be newly formed. Given these features, we conjecture that the ellipsoid ultrastructures are PAACs and the allantoid ultrastructures are their precursors.

We took advantage of our FIB-SEM series to investigate whether PAACs are intracellular compartments that develop within a pre-enterocyte, akin to the large apical endosomes (vacuolar apical compartments/apicosomes) observed in mammalian cells (Gilbert and Rodriguez-Boulan, 1991; Taniguchi et al., 2017; Vega-Salas, 1988) or intercellular compartments that develop between a pre-enterocyte and its mature enterocyte neighbors. We selected series that captured the nearcomplete volume of individual PAACs or PAAC precursors, and we analyzed their membrane topologies slice-by-slice (Figs. 5B and 5C). We also generated a volumetric rendering of a 200-slice FIB-SEM tomographic series that contained a PAAC, a PAAC precursor, and their associated preenterocyte within a tissue volume of $40.2 \mu \mathrm{m} \times 23.9 \mu \mathrm{m} \times 8 \mu \mathrm{m}$ (Fig. 5D and Video 6). 
These analyses invariably uncovered a region in which pre-enterocyte and mature enterocyte membranes separate from each other to form the PAAC's lumenal space (Fig. 5B and Video 6). Thus, PAACs are intercellular. The PAAC lumen is surrounded by an expansive SJ that adheres the preenterocyte to mature enterocytes; this SJ separates the PAAC from the gut's central lumen. The ultrastructure of the PAAC-associated SJ is consistent with the SJs we observed in immunostained, Stage 3 pre-enterocytes (Fig. 3 and Video 3). PAAC precursors-even very small ones-also comprise an intercellular lumen surrounded by an expansive SJ. We did not observe any microvillilined compartments that were entirely intracellular. The similar topology of PAACs and PAAC precursors suggests that PAACs initiate via de-adhesion of apposing plasma membranes rather than fusion of an intracellular compartment with the SJ.

\section{PAACs' split apical/basolateral polarity is unique for a lumen-encompassing structure}

PAAC-forming pre- and mature enterocytes make markedly unequal contributions to the PAAC's overall morphology. The pre-enterocyte plasma membrane represents the vast majority of a PAAC's total surface area. It folds inward at nearly 180 degrees (arrow in Fig. 5B) to create a deep invagination into the pre-enterocyte cytoplasm. This invagination accounts for most of the PAAC's lumenal volume and evokes a scenario in which PAAC development is driven by inward folding of the pre-enterocyte plasma membrane. In contrast to the structured folds of the pre-enterocyte membrane, the mature enterocyte membranes are amorphous and rest like a blobby lid atop the PAAC lumen (Fig. 5B). These differences are even more extreme in PAAC precursors (Fig. 5C).

The contrast between the structured pre-enterocyte membrane and the amorphous enterocyte membrane corresponds to a second-unprecedented-asymmetry of PAACs: their lumenal polarity is split. The PAAC's pre-enterocyte membrane is apical while the partner enterocyte membrane(s), which lacks apical markers (Video 3) and microvilli (Figs. 5B \& 5C, and Video 6), is by default basolateral. To our knowledge, this combination has not previously been reported for any epithelial lumen either in cell culture or in vivo. Rather, epithelial lumens to date have been either uniformly apical (Blasky et al., 2015; Datta et al., 2011; O’Brien et al., 2002), or, in some rare, experimentally induced cases, uniformly basolateral (Lowery et al., 2009; Wang et al., 1990). However, these prior studies examined lumens that form between cells at similar differentiation states; we conjecture that the PAACs' unique asymmetries derive from their origin between cells at distinct differentiation states.

\section{Enteroblasts must form SJs to integrate and mature into enterocytes}

Our data reveal that as stem cell daughters differentiate, they initiate epithelial integration by forming new, sheet-like SJs with mature neighbor cells. What happens when SJ formation is blocked? To examine this question, we generated "SJ-less" enteroblasts and assessed their ability to integrate and differentiate. We inhibited expression of the SJ component ssk specifically in enteroblasts by using the enteroblast driver $S u(H)$-GAL4 to express a UAS-sskRNAi transgene under 
control of temperature-sensitive GAL80 $0^{\text {ts }}$ (McGuire et al., 2003) (genotype henceforth referred to as $\left.S u(H)^{t s}>s s k R N A i\right)$. A $U A S-G F P$ transgene was also included to identify the RNAi-expressing cells. The sskRNAi hairpin was expressed from days 0-4 of adult life, after which midguts were harvested and analyzed. To confirm that sskRNAi prevented SJ formation, we performed immunostaining for another SJ component, Coracle. Whereas Coracle localized to the apex of $S u(H)^{t_{s}}$-expressing control cells, it localized to the cytoplasm of $S u(H)^{t s}>s s k R N A i$ cells (Figs. 6A \& 6B). This redistribution implies that sskRNAi expression prevents proper formation of SJs.

$\mathrm{Su}(H)^{t_{s}}>$ sskRNAi cells categorically failed to integrate into the gut epithelium. Instead of reaching the gut's central lumen, these cells accumulated beneath the gut's SJ network (Figs. 6A \& $6 \mathrm{~B})$. Although this basal localization is typical of enteroblasts, $\mathrm{Su}(H)^{t_{s}}>s s k R N A i$ cells did not arrest in an enteroblast state. Rather, they grew in volume and endoreplicated their nuclei (Fig. 6C and Figs. S5A \& S5B), two behaviors characteristic of pre-enterocytes (Fig. 3, Stages $3 \& 4$ ). Yet unlike preenterocytes, $S u(H)^{1 s}>$ sskRNAi cells did not adopt a cuboidal or columnar shape and instead became blob-shaped. Similar behaviors were exhibited by MARCM-generated stem cell clones (Lee and Luo, 1999) that were genetically null for SJ components tsp2A (Chen et al., 2018) and mesh (Fig. S5E \& $\mathrm{S5F}$ ). Thus even as SJ-less cells achieve mature size, they do not become part of the epithelium.

The indeterminate morphology of $S u(H)^{1 s}>$ sskRNAi cells was accompanied by inappropriate, mixed expression of fate-specific transcription factors. Whereas the stem cell/enteroblast transcription factor Sox100B (Doupé et al., 2018; Jin et al., 2020; Meng et al., 2020) was expressed by both control $S u(H)$ and $S u(H)^{t_{s}}>$ sskRNAi cells (Figs. S5A \& S5B), the enterocyte transcription factor Pdm1 (Dantoft et al., 2013; Korzelius et al., 2014; Lee et al., 2009) was absent from control $S u(H)$ cells yet expressed in $\mathrm{Su}(H)^{t s}>$ sskRNAi cells (Figs. S5C \& S5D). Similar, mixed patterns of marker expression were observed by $\mathrm{Xu}$ and colleagues upon enteroblast-specific depletion of the SJ component tsp2A (Xu et al., 2019).

Altogether, these findings imply that SJ-less cells become trapped in an abnormal, hybrid cellular state in which the distinct features of enteroblasts and enterocytes co-exist abnormally.

\section{Cell growth is required for integration, independent of SJs}

Having found that growth is not sufficient for cells to integrate, we asked whether integration requires cell growth. Cell growth during the enteroblast-enterocyte transition is controlled by the Tsc/Rheb/Tor pathway (Amcheslavsky et al., 2011; Kapuria et al., 2012; Nie et al., 2015; Quan et al., 2013; Xiang et al., 2017). Tor pathway activation in enteroblasts can be visualized by immunostaining for the phosphorylated isoform of the Tor kinase substrate eIF4E Binding Protein (phospho-4EBP) (Kapuria et al., 2012). When Tor is inactivated via overexpression of its inhibitor, Tsc1/2, 4EBP is not phosphorylated (Fig. 6F) and differentiation-associated growth is blocked (Kapuria et al., 2012). 
We found that growth of SJ-less cells, like growth of normal enteroblasts, depends on Tor. Phospho-4EBP immunostaining showed that $S u(H)^{t s}>$ sskRNAi cells are Tor-activated, akin to $S u(H)$ control cells (Figs. 6D \& 6E). When we conditionally overexpressed tsc1/2 in either control cells $\left(S u(H)^{t s}>t s c 1 / 2\right)$ or ssk knockdown cells $\left(S u(H)^{t s}>s s k R N A i, t s c 1 / 2\right)$, we abrogated phospho-4EBP and inhibited cell growth (Figs. 6F \& 6G).

We next examined whether Tor inactivation and consequent growth inhibition affects the ability of cells to integrate. We assessed $S \mathrm{~J}$ formation in $S u(H)^{t_{s}}>t_{s c 1} 1 / 2$ cells by immunostaining guts for Ssk and the $S u(H)$-lacZ reporter and determining whether the Ssk signal contacted the apex of $\beta$-galactosidase-labelled cells. Whereas $95 \%$ of control Su(H) cells formed SJs, only $46 \%$ of $S u(H)^{t s}>t s c 1 / 2$ cells did. Revealingly, no $S u(H)^{t_{s}}>t s c 1 / 2$ cells progressed beyond Stage 1 . Thus, SJ initiation is not sufficient for integration to progress; enteroblast growth is also necessary. While the precise contribution of growth is currently unclear, it may fuel expansion of the umbrella SJ or to initiate PAAC formation.

\section{Organ-scale impacts of blocked cellular integration}

Organ renewal requires that new cells integrate successfully into the epithelium. When cell integration is blocked, what are consequences to organ-scale cellular equilibrium? We first asked whether blocking integration causes undifferentiated cells to accumulate abnormally in the tissue (Fig. 7A). When animals are maintained under stable, ad libitum conditions, $\mathrm{Su}(\mathrm{H})^{+}$cells typically comprise $\sim 10 \%$ of total cells in the midgut R4 region (O'Brien et al., 2011; Viitanen et al., 2021). This proportion essentially doubled when we blocked integration by inhibiting new SJ formation (19.1\% $\pm 5.5 \%$ of total cells in $S u(H)^{t_{s}}>$ sskRNAi guts; $9.3 \% \pm 2.8 \%$ in control guts). By comparison, the proportion of $\mathrm{Su}(\mathrm{H})^{+}$cells remained nearly normal when we blocked integration by inhibiting cell growth $\left(12.0 \pm 2.8 \%\right.$ in $S u(H)^{t s}>t s c 1 / 2$ guts). Concomitant inhibition of both $S J$ formation and cell growth resembled growth inhibition alone $\left(12.0 \pm 3.2 \%\right.$ of total cells in $S u(H)^{t s}>$ sskRNAi, tsc1/2guts were $\mathrm{Su}(\mathrm{H})$-lac $\mathrm{Z}^{+}$). Thus, whether integration-blocked cells accumulate in the tissue depends on the means through which integration was blocked. One possible reason may be differences in differentiation state of the integration-blocked cells. Early-stage enteroblasts, which still adhere strongly to their mother stem cell, can repress subsequent mother cell divisions (Choi et al., 2011), and Tsc1/ 2 overexpression-but not SJ inhibition-arrests differentiation at an early stage ((Kapuria et al., 2012) and Figs. 6C \& S5C-G). This early-stage arrest may enable growth-inhibited cells to repress production of additional daughter cells.

We next examined whether blocking integration alters the organ's total number of cells (Fig 7B). Comprehensive counts of DAPI-labeled nuclei in the midgut R4ab region revealed that total cell number remains normal when new cells cannot integrate, even for guts in which integrationblocked cells accumulate abnormally $\left(1997 \pm 489\right.$ cells in control $S u(H)^{t s}$ guts compared $1960 \pm 398$, $2067 \pm 210$ cells, and $1611 \pm 299$ cells in $S u(H)^{t_{s}}>$ sskRNAi, Su $(H)^{t_{s}}>t s c 1 / 2$, and $S u(H)^{t_{s}}>$ sskRNAi, tsc1/2 
guts, respectively). We speculate that feedback mechanisms inherent to organ-scale control of total cell number (Akagi et al., 2018; Jin et al., 2017; Liang et al., 2017) 'sense' unintegrated cells and exert a compensatory effect on cellular equilibrium.

\section{DISCUSSION}

Epithelial organs maintain a leakproof barrier between the interior body and the external environment even while continuously replacing the cells that directly contact this environment. In many barrier epithelia, these replacement cells derive from basal stem cells and are born without a lumenal-apical surface or occluding junctions, two structures that are essential for barrier integrity. Consequently, daughters must generate these structures de novo and integrate into the barrier as they differentiate.

We examined this process at ultra-fine spatial resolution during physiological turnover of the Drosophila intestinal epithelium. Our analyses led to a previously undescribed mechanism that we term PAAC-mediated integration (Fig. 7D): The new cell forms a broad, umbrella-shaped SJ that serves as a transient niche for biogenesis of the cell's future lumenal-apical surface (the PAAC). When the new cell is sufficiently mature, the umbrella SJ retracts and the PAAC lumen fuses with the gut lumen, exposing the cell's apical membrane to the external environment. In contrast to a prior model of radial intercalation (Fig. 7D), PAAC-mediated integration enables stem cell daughters to form barrier structures in a space sheltered from the contents of the gut lumen-a potentially crucial safeguard for an epithelium that is simultaneously physiologically active and continuously renewing.

\section{PAAC architecture: Implications for epithelial lumen formation}

Lumens are defining features of epithelial tubes, and the molecular and cellular events that drive lumen formation are a topic of intense interest. Our current understanding of lumen formation comes from studying epithelial cells that are at similar states of differentiation (Blasky et al., 2015; Datta et al., 2011; Overeem et al., 2015; Sigurbjörnsdóttir et al., 2014). PAACs provide a first, finegrained example of how lumens form between cells that are at disparate states of differentiation. This fate difference likely underlies the PAACs' two distinctive characteristics, structural asymmetry and split polarity. Below, we speculate how these PAAC-specific characteristics may shed new light on lumen-forming mechanisms in general.

PAACs are, to the extent we can determine, the first type of intercellular lumen that exhibits split polarity-the membranes that form PAACs alternate between apical identity (the preenterocyte) and basolateral identity (mature enterocytes) (Figs. 3, 5 \& 7D; and Video 6). By comparison, all epithelial lumens of which we are aware are normally enclosed by membranes that are exclusively apical (Blasky et al., 2015; Datta et al., 2011; Overeem et al., 2015; Sigurbjörnsdóttir et al., 2014). Our finding that PAACs' mature enterocyte membranes do not form a secondary apical 
domain is surprising because cells that contact multiple lumens in developing epithelia form a corresponding apical domain for each lumen (Alvers et al., 2014; Bagnat et al., 2007; Bryant et al., 2010). One possible explanation is that terminally differentiated epithelial cells actively repress secondary apical domains whereas epithelial cells in developmental contexts do not. Another, nonexclusive, possibility is that all lumens transiently exhibit split apical/basal polarity at their earliest stage-one lumen-forming cell initiates an apical domain prior to the others-but that this stage is, in most cases, extremely short-lived, so it has not been detected previously.

PAACs' second striking feature is their extreme structural asymmetry: pre- and mature enterocyte membranes, despite being bonded at their edges by the same $\mathrm{SJ}$, acquire shapes that are extreme opposites. The pre-enterocyte PAAC membrane, which grows dramatically and invaginates deeply into the cytoplasm of the differentiating cell, convolutes into sharp folds and broad curves. This structure, which is superimposed onto the membrane's fine-scale microvillar folds, sets the volume of the PAAC. The mature enterocyte membranes, by contrast, appear largely passive. They sit like a lid atop the neck of the pre-enterocyte invagination and do not appear to morph or expand during differentiation (e.g., compare the nascent and advanced PAACs in Fig. 5 and Video 6).

These two features, split apical/basolateral polarity and structural asymmetry, provide insight into opposing models of lumen formation. The structural asymmetry of PAACs is incompatible with the prevailing model of lumen formation, in which hydrostatic pressure drives lumen growth (Chan et al., 2019; Dasgupta et al., 2018; Dumortier et al., 2019; Ruiz-Herrero et al., 2017; Yang et al., 2021), because lumens generated by hydrostatic pressure are uniformly convex (Vasquez et al., 2021). Rather, this asymmetry evokes a recently proposed alternative mechanism in which expansion of apical membrane surface drives lumen growth in a pressure-independent manner (Vasquez et al., 2021). Indeed, since growth of the PAAC lumen is accounted for by apical surface expansion of a single cell, PAACs may provide an informative case study of apical surfacedriven growth. Identifying the molecular signals that target and stabilize new PAACs will aid in exploring these scenarios.

\section{A trade-off between barrier integrity and junction-forming efficiency}

In both PAAC-mediated integration and radial intercalation, single cells assimilate into an epithelium through basal-to-apical movement. Why do distinct mechanisms exist to reach the same cellular endpoint? We speculate that, in general, basal-to-apical assimilation requires a trade-off between integration speed and barrier integrity. A given mechanism may favor one of these qualities at the expense of the other. In principle, a spectrum of mechanisms enables tissues to employ the mechanism that is best suited to their specific biological context.

In this schema, radial intercalation is rapid and parsimonious. It occurs over time scales of minutes or a few hours. New junctions initiate within the pre-existing junctional network and expand directly into their final morphology, an apico-lateral band. Intriguingly, all examples of 
radial intercalation described in the literature take place in developing epithelia (Merzdorf et al., 1998; Deblandre et al., 1999; Stubbs et al., 2006; Voiculescu et al., 2007; McMahon et al., 2008; Campbell et al., 2010). Because embryos themselves are housed in a protective environment (such as an egg or a womb), cells in embryonic tissues can display immature junctions and incipient microvilli at the organ's apical surface without risking exposure to the external environment.

PAAC-mediated integration is slower and, since it involves building and then retracting a temporary scaffold, likely less efficient. We estimate that typical time frames for PAAC-mediated integration are $>24 \mathrm{~h}$, based on changes in nuclear size of stem cell daughters over time (Koyama et al., 2020). (Indeed, this $>24 \mathrm{~h}$ time frame presented a challenge for Windowmount live imaging, which typically yields movies $\sim 8-20 \mathrm{~h}$ in duration.) A differentiating cell may require this time to construct the umbrella SJ and microvilli-lined PAAC_-large structures that will undergo extensive remodeling in subsequent stages. The indirect, more complex nature of PAAC-mediated integration provides an additional layer of protection for differentiating cells-a potentially worthwhile tradeoff for a functionally active organ that continuously processes substances from the external environment.

How do SJs guide differentiating cells into the epithelial sheet? One appealing notion is that they exert myosin-based pulling forces that draw differentiating cells toward the lumen (Varadarajan et al., 2019; Yu and Zallen, 2020). We were, however, unable to identify any impact on integration following enteroblast-specific inhibition of Rho kinase (Rok; data not shown). Since Rok is an essential activator of myosin contractility, this finding implies that myosin-based forces are not required in the integrating cell. A second possibility is that myosin-based pulling forces, or some other cytoskeletal regulator, is required in mature neighbor cells to aid the basal-to-apical movement of differentiating cells. Since SJs bond together mature and differentiating cells, they are wellpositioned to coordinate these two cell types during integration. Finally, SJs may serve to polarize growth and / or cytoskeletal assembly along the apical-basal axis of the differentiating cell (Madara, 1987).

\section{Diverse epithelial architectures may use a diversity of cell assimilation mechanisms}

Numerous barrier epithelia, including mammalian trachea, cornea, and olfactory lining, have a cellular organization like the fly gut (Chepko and Dickson, 2003; Chepko and Smith, 1997; Cotsarelis et al., 1989; Evans and Moller, 1991; Leung et al., 2007; Michael J. Evans, 2001; Rock et al., 2009; Sekiya et al., 1988; Tsujimura et al., 2002). All these tissues are renewed by basally localized stem cells that lack occluding junctions and lumenal-apical surfaces. Their daughter cells thus all face the same architectural challenge of integrating seamlessly into the barrier while they differentiate. Whether they overcome this challenge through PAAC-mediated integration, like the fly gut, or through some other, perhaps as-yet-undefined, mechanism will be an interesting question for future investigation. 
In considering how epithelial architecture affects new cell integration, it is notable that two of the best-understood barrier epithelia, mammalian intestine and lung alveoli, sidestep the challenge of barrier integration entirely. In these tissues, stem cells possess both occluding junctions and lumenal-apical surfaces, and daughter cells symmetrically inherit these structures from their mother (Fig. 7D) (DeMaio et al., 2009; Fleming et al., 2007; Jinguji and Ishikawa, 1992; McKinley et al., 2018). Symmetric inheritance is morphogenetically parsimonious, but it requires the abscission of existing junctional septa and creation of new septa at the new daughter-daughter interface. Since this remodeling happens at the lumenal surface, it might produce potential weak points in the barrier. Thus, at first glance, the fact that mammalian intestine and lung use symmetric inheritance to assimilate new cells seems at odds with the idea that physiologically active epithelia need extra safeguards to protect barrier integrity.

We speculate, however, that this potential risk is mitigated by these tissues' particular architecture; namely, deeply recessed niches-intestinal crypts and terminal alveolar endbuds-in which the lumen-exposed stem cells reside. Crypts and endbuds are secluded from bulk lumenal flow, which provides their resident stem cells with built-in protection that stem cells in other epithelia lack. This built-in protection conceivably affords stem cell daughters the simplicity of directly inheriting barrier structures from their mother cell. In this light, PAACs may be seen as a cellular-scale solution for epithelia that lack recessed stem cell niches, the tissue-scale solution for protecting new cells. As such, our findings spotlight the intimate relationship between physiological function, organ form, and cellular differentiation and morphogenesis.

\section{MATERIALS and METHODS}

\section{Drosophila husbandry}

Mated adult female flies were used in all experiments. Crosses utilizing the TARGET system (GAL4/GAL80 ${ }^{\text {ts }}$ ) were performed at $18^{\circ} \mathrm{C}$ (McGuire et al., 2003). Upon eclosion, adult animals were temperature shifted to $29^{\circ} \mathrm{C}$ for 4 days to inactivate GAL80 ${ }^{\text {ts }}$ and induce GAL4-mediated expression. Midguts were harvested for immunostaining 4 days after induction. Flies used for immunofluorescence were raised on standard molasses medium at $18^{\circ} \mathrm{C}$. Upon eclosion, they were shifted to $29^{\circ} \mathrm{C}$. Midguts were harvested for immunostaining 4 days after eclosion.

\section{Immunohistochemistry and sample preparation for confocal microscopy}

Dissected guts were fixed in 4\% formaldehyde in PBS ( $\mathrm{pH}$ 7.4) at room temperature for 1 hour, immunostained, and mounted as previously described (O'Brien et al., 2011). Primary antibodies: mouse anti-Armadillo (1:100, DSHB N2 7A1), rabbit anti-Snakeskin (1:1000, gift from Furuse lab), mouse anti-Coracle (1:50, DSHB C615.16), mouse anti- $\beta$-galactosidase (1:400, Promega Z3781), rabbit anti-Phospho4EBP1 (1:500, Cell Signaling). Secondary antibodies: donkey anti-rabbit IgG conjugated to Alexa 555 and donkey anti-mouse IgG conjugated to Alexa 647 (1:1000, Invitrogen A-31572 and A-31571, respectively). Nuclei were stained with DAPI (LifeTechnologies D1306). Samples were incubated with primary antibody overnight at $4^{\circ} \mathrm{C}$ in PBT (PBS with $3 \%$ Triton X-100 (Sigma-Aldrich X100-100 mL)) with 5\% NGS (Capralogics GS0250), washed 3 times in PBT, then 
incubated with secondary antibody for 4 hours at room temperature in PBT with 5\% NGS. Samples were mounted in ProLong (LifeTechnologies P36984) and stored at $-20^{\circ} \mathrm{C}$ until imaging.

\section{Induction of MARCM clones}

Heat-shock MARCM clones (Lee and Luo, 1999) were generated by collecting adult flies 1224 hours post-eclosion and performing two $45-\mathrm{min}, 37^{\circ} \mathrm{C}$ heat shocks separated by an 8 -min chill on ice. Flies were returned to $25^{\circ} \mathrm{C}$ for 4 days, then dissected and analyzed.

\section{Fixed sample imaging}

Fixed samples were imaged on a Leica SP8 WLL confocal microscope with a 63x HC PL APO CS2 oil objective. Serial optical sections were taken at $0.5 \mu \mathrm{m}$ intervals through the entirety of wholemounted, immunostained midguts.

\section{Quantitation of SJ-contacting and non-contacting cells}

Enteroblasts in the midgut R4ab region (also known as P1/2) (Buchon et al., 2013; Marianes and Spradling, 2013; O'Brien, 2013) were visualized and counted using ImageJ/Fiji (Schindelin et al., 2012). The R4ab region was identified using morphological landmarks. SJs were identified by immunostaining for the $\mathrm{SJ}$ component Snakeskin. $\mathrm{Su}(\mathrm{H})-\mathrm{lacZ}^{+}\left(\beta-\mathrm{Gal}^{+}\right)$cells were recognized as enteroblasts by visual inspection. To categorize enteroblasts as SJ-contacting or non-contacting, each enteroblast was analyzed through Fiji Orthogonal View. Enteroblasts were defined as SJ-contacting cells if the $\beta-\mathrm{Gal}^{+}$signal was juxtaposed and/or displayed overlap with apical Snakeskin signal in $\mathrm{XY}, \mathrm{XZ}$ and $\mathrm{YZ}$ planes. Enteroblasts were defined as SJ non-contacting cells if they lacked these criteria.

\section{Measurements of cell volume}

To measure volumes of $\mathrm{Su}(\mathrm{H})$-lac $\mathrm{Z}^{+}$cells, tissues were fixed, immunostained using anti- $\beta$ galactosidase antibody, mounted, and subjected to volumetric confocal imaging. After initial processing in Fiji, files were imported to Bitplane Imaris v.8.7. Volumes of $\mathrm{Su}(\mathrm{H})-\mathrm{lac} \mathrm{Z}^{+}$cells were determined by creating a surface for each cell using the Imaris contour tool and then measuring the enclosed volume.

\section{Ovary dissection and staining}

Egg chambers were dissected in phosphate-buffered saline (PBS pH 7.4) + 0.1\% Triton X-100 and incubated for 2 hours in $1 \mathrm{mM}$ latrunculin B (LatB; Sigma). They were then fixed $20 \mathrm{~min}$ in $4 \%$ PFA (in PBS pH 7.4), incubated 2 hours in a 1:250 dilution of TRITC-conjugated phalloidin (Molecular Probes, Eugene, OR), and subsequently imaged on a Zeiss LSM 700 confocal microscope.

\section{Total cell and total enteroblast counts}

To perform total cell counts and total enteroblast counts of R4ab, confocal image stacks were digitally isolated in Fiji. Bitplane Imaris was used generate three-dimensional organ reconstructions, and individual cells were comprehensively counted by mapping signals for DAPI (for total cell counts) or $\mathrm{Su}(\mathrm{H})$-lacZ (for total enteroblast counts) to Imaris surface objects. Imaris-recognized surfaces were confirmed through visual inspection and manually adjusted when needed for accuracy. 


\section{In vivo live imaging and movie analyses}

Live imaging was performed on 2-3-day old adult females as described previously (Martin et al., 2018), with the following modifications: For Video 4, $20 \mathrm{nM} \mathrm{RU486}$ and $10 \mu \mathrm{g} / \mathrm{mL}$ Isradipine were added to the imaging media to induce GeneSwitch5966 expression and reduce intestinal peristalsis, respectively. For Video 5, $10 \mu \mathrm{g} / \mathrm{mL}$ Isradipine was added to the imaging media to reduce intestinal peristalsis.

Videos were acquired with a LSM Leica SP5 with a HCX APO L 20x / 1.00W lens, controlled by LAS AF software. Confocal sections were taken every 15 mins with z-steps of $1.01 \mu \mathrm{m}$ (Video 4) and $2.98 \mu \mathrm{m}$ (Video 5). Videos were processed on a Windows computer (Windows 10 Education) with a $3.70 \mathrm{GHz}$ quad-core Intel Xeon processor and $256 \mathrm{~GB}$ memory. Videos were initially processed in Fiji and subsequently visualized in volumetric format and analyzed in Bitplane Imaris. For Video 4, the following Fiji plugins were applied: 1) Stack Sorter (https: / / www.optinav.info/Stack-Sorter.htm), to correct the alignment of out-of-order slices captured during a peristaltic contraction, 2) StackReg (Arganda-Carreras et al., 2006) to correct for whole-organ X-Y movements, 3) Correct 3D Drift (Parslow et al., 2014) to correct for global volume movements, and 4) TrakEM2 (Cardona et al., 2012) to perform manual X-Y alignment for slices that could not be registered automatically. The latter 3 plugins were applied iteratively as needed. For Video 5, Stack Sorter, StackReg, and Correct 3D Drift were used. The latter two plugins were applied iteratively as needed.

\section{Measurements of cross-sectional cell area in live movies}

The cross-sectional area of the integrating $\mathrm{Su}(\mathrm{H})$-mCherry ${ }^{+}$cell at each timepoint in Video 4 was determined as follows: The cell's largest cross-sectional plane at each time point was identified by visual inspection. FIJI Measure was used to manually outline the mCherry signal in this plane and to measure the enclosed area.

\section{Sample preparation for FIB-SEM}

Fly guts were dissected in PBS and immediately processed as previously described (Daniel et al., 2018; Kolotuev, 2014). Briefly, the samples were fixed in 1\% formaldehyde, 2.5\% glutaraldehyde in $0.1 \mathrm{M}$ phosphate buffer (PB) for 2 hours at room temperature, then incubated for 1 hour in $2 \%$ $(\mathrm{wt} / \mathrm{vol}$ ) osmium tetroxide and 1.5\% (wt/vol) $\mathrm{K} 4[\mathrm{Fe}(\mathrm{CN}) 6]$ in PB followed by 1 hour in $1 \%$ (wt $/ \mathrm{vol}$ ) tannic acid in $100 \mathrm{mM}$ cacodylate buffer, then 30 minutes in $2 \%$ (wt/vol) osmium tetroxide in water followed by $1 \%(\mathrm{wt} / \mathrm{vol}$ ) uranyl acetate for 2 hours at room temperature. After the dehydration cycles, samples were embedded in Epon-Araldite mix. Samples were flat embedded to assure the targeting of the region of Interest during the sectioning step.

\section{Sample preparation for CLEM}

To preserve native fluorescence for correlative light/electron microscopy, samples were subjected to high-pressure freezing followed by rapid freeze-substitution, as previously described (Kolotuev, 2014; Kolotuev et al., 2010). Dissected guts were immediately transferred to large high pressure freezing carriers filled with $20 \%$ bovine serum albumin for cryo-protection and frozen using the standard procedure according to the manufacturer's instructions (High Pressure Freezing Machine HPF Compact 02, Engineering Office M. Wohlwend GmbH, Sennwald, Switzerland). Samples were substituted in an AFS2 machine (Leica) with $0.1 \%$ uranyl acetate diluted in anhydrous acetone and embedded in HM20 acrylic resin mix (Electron Microscopy Sciences). To assure precise orientation of the samples, the flat embedding procedure was used (Kolotuev, 2014). 


\section{Electron microscopy image acquisition and analysis}

Polymerized flat blocks were trimmed using a $90^{\circ}$ diamond trim tool (Diatome, Biel, Switzerland) mounted on a Leica UC6 microtome. Transmission electron microscopy samples were analyzed with an FEI CM100 electron microscope operated at 80kV, equipped with a TVIPS camera piloted by the EMTVIPS program.

Samples for CLEM were sectioned at 100-150 nm thickness and transferred to wafers using an array tomography protocol (Burel et al., 2018; Kolotuev and Micheva, 2019). CLEM wafers were first imaged for fluorescence signal using a Zeiss fluorescent microscope equipped with DAPI and GFP filters using 20x and 60x objectives. To analyze the ultrastructure, sections on wafer were contrasted with uranyl acetate and lead citrate and observed using an FEI Quanta 250 FEG scanning electron microscope (FEI, Eindhoven). The imaging settings were as follows: accelerating voltage, $10 \mathrm{kV}$; spot size, 5; image dimensions, 4096x4096; pixel dwell time, $10 \mu \mathrm{s}$.

FIB-SEM tomography was done with a Helios 650 (FEI, Eindhoven). Fibbing conditions were $30 \mathrm{keV}, 770 \mathrm{pA}, 30-40 \mathrm{~nm}$ slice thickness (specified in text for each experiment) at a tilt angle of $52^{\circ}$ and a working distance of $13 \mathrm{~mm}$. For imaging the block face was tilted normal towards the electron beam (Kizilyaprak et al., 2015). The imaging conditions were: $2 \mathrm{keV}, 800 \mathrm{pA}, 20 \mu$ s dwell time, with a frame size of $6144 \times 4096$ and a pixel size of $9.7 \mathrm{~mm}$. For publication, the image contrast was inverted.

IMOD (Kremer et al., 1996) was used to convert raw data from sequential sections to an MRC file stack and used for alignment of serial sections and volumetric rendering. Adobe Photoshop was used for image adjustment, layers superposition, annotations, pseudo-coloring of image zones, and volume reconstructions.

\section{Volumetric rendering of FIB-SEM images}

Serial sections were stacked and aligned using the cross-correlation function of IMOD, which was also used to trace and reconstruct specific regions. Drawing tools were used for outlining subcellular features (e.g., septate junctions, plasma membrane, nuclei, PAAC) on the EM layers. The 3D reconstruction surfaces were Meshed in Model View / Objects tool. Images were captured using the Model View/Movie Montage tool and reformatted into .avi format using Fiji.

\section{FUNDING SOURCES}

P.M.R. was supported by a Stanford Bio-X Bowes Graduate Fellowship, an EMBO ShortTerm Travelling Fellowship, and a Stanford DARE Graduate Fellowship (Diversifying Academia, Recruiting Excellence). The authors acknowledge the financial support by the Faculty of Biology and Medicine of the University of Lausanne and of the Swiss National Science Foundation, R'Equip Grant 316030_128692. This work was supported by NIH R01GM116000-01A1, NIH R35GM14188501, and ACS RSG-17-167-01 to L.E.O.

\section{ACKNOWLEDGEMENTS}

We are grateful to Allison Bardin, David Bilder, Nicolas Buchon, Joaquin de Navascues, Mikio Furuse, Yoshihiro Inoue, Henri Jasper, Sarah Siegrist, Norbert Perrimon, Nicolas Tapon, Charles $\mathrm{Xu}$, and Drosophila stock centers (Bloomington Drosophila Stock Center (NIH P40OD018537), Vienna Drosophila Resource Center (Dietzl et al., 2007), Kyoto Drosophila Genomics and Genetic Resoruces)for fly stocks; Mikio Furuse, Claire Thomas, Steven Russell, and Xiaohang Yang for antibodies; and Jon Mulholland and Kitty Lee for microscopy support. Confocal 
microscopy was performed at the Stanford Beckman Cell Sciences Imaging Facility (NIH 1S10OD01058001A1, NIH 1S10OD010580). We thank David Bryant, Tobias Reiff, Daniel St. Johnston, Jia Chen, and members of the O'Brien lab for invaluable discussions. Fly extract was obtained from the Drosophila Genomics Resource Center (NIH 2P40OD010949).

\section{REFERENCES}

Akagi, K., Wilson, K.A., Katewa, S.D., Ortega, M., Simons, J., Hilsabeck, T.A., Kapuria, S., Sharma, A., Jasper, H., and Kapahi, P. (2018). Dietary restriction improves intestinal cellular fitness to enhance gut barrier function and lifespan in D. melanogaster. PLOS Genetics 14, e1007777.

Alvers, A.L., Ryan, S., Scherz, P.J., Huisken, J., and Bagnat, M. (2014). Single continuous lumen formation in the zebrafish gut is mediated by smoothened-dependent tissue remodeling. Development 141, 1110-1119.

Amcheslavsky, A., Ito, N., Jiang, J., and Ip, Y.T. (2011). Tuberous sclerosis complex and Myc coordinate the growth and division of Drosophila intestinal stem cells. The Journal of Cell Biology 193, 695-710.

Arganda-Carreras, I., Sorzano, C.O.S., Marabini, R., Carazo, J.M., Ortiz-de-Solorzano, C., and Kybic, J. (2006). Consistent and elastic registration of histological sections using vector-spline regularization. In Computer Vision Approaches to Medical Image Analysis, (Berlin, Heidelberg: Springer, Berlin, Heidelberg), pp. 85-95.

Bachmair, A., Finley, D., and Varshavsky, A. (1986). In vivo half-life of a protein is a function of its amino-terminal residue. Science 234, 179-186.

Bagnat, M., Cheung, I.D., Mostov, K.E., and Stainier, D.Y.R. (2007). Genetic control of single lumen formation in the zebrafish gut. Nature Cell Biology 9, 954-960.

Bardin, A.J., Perdigoto, C.N., Southall, T.D., Brand, A.H., and Schweisguth, F. (2010). Transcriptional control of stem cell maintenance in the Drosophila intestine. Development 137, 705-714.

Baumann, O. (2001). Posterior midgut epithelial cells differ in their organization of the membrane skeleton from other drosophila epithelia. Exp Cell Res 270, 176-187.

Blasky, A.J., Mangan, A., and Prekeris, R. (2015). Polarized Protein Transport and Lumen Formation During Epithelial Tissue Morphogenesis. Annu. Rev. Cell Dev. Biol. 31, 575-591.

Bobinnec, Y., Marcaillou, C., Morin, X., and Debec, A. (2003). Dynamics of the endoplasmic reticulum during early development of Drosophila melanogaster. Cell Motility 54, 217-225.

Bryant, D.M., Datta, A., Rodríguez-Fraticelli, A.E., Peränen, J., Martín-Belmonte, F., and Mostov, K.E. (2010). A molecular network for de novo generation of the apical surface and lumen. Nat Cell Biol 12, 1035-1045.

Buchon, N., Osman, D., David, F.P.A., Yu Fang, H., Boquete, J.-P., Deplancke, B., and Lemaitre, B. (2013). Morphological and molecular characterization of adult midgut compartmentalization in Drosophila. Cell Rep 3, 1725-1738.

Burel, A., Lavault, M.-T., Chevalier, C., Gnaegi, H., Prigent, S., Mucciolo, A., Dutertre, S., Humbel, B.M., Guillaudeux, T., and Kolotuev, I. (2018). A targeted 3D EM and correlative microscopy method using SEM array tomography. Development 145. 
Campbell, K., Casanova, J., and Skaer, H. (2010). Mesenchymal-to-epithelial transition of intercalating cells in Drosophila renal tubules depends on polarity cues from epithelial neighbours. Mech Dev 127, 345-357.

Chan, C.J., Costanzo, M., Ruiz-Herrero, T., Mönke, G., Petrie, R.J., Bergert, M., Diz-Muñoz, A., Mahadevan, L., and Hiiragi, T. (2019). Hydraulic control of mammalian embryo size and cell fate. Nature $571,112-116$.

Chen, J., Sayadian, A.-C., Lowe, N., Lovegrove, H.E., and St Johnston, D. (2018). An alternative mode of epithelial polarity in the Drosophila midgut. PLoS Biology 16, e3000041.

Chepko, G., and Dickson, R.B. (2003). Ultrastructure of the putative stem cell niche in rat mammary epithelium. Tissue and Cell 35, 83-93.

Chepko, G., and Smith, G.H. (1997). Three division-competent, structurally-distinct cell populations contribute to murine mammary epithelial renewal. Tissue and Cell 29, 239-253.

Choi, N.-H., Lucchetta, E., and Ohlstein, B. (2011). Nonautonomous regulation of Drosophila midgut stem cell proliferation by the insulin-signaling pathway. Proceedings of the National Academy of Sciences 108, 18702-18707.

Cotsarelis, G., Cheng, S.-Z., Dong, G., Sun, T.-T., and Lavker, R.M. (1989). Existence of slow-cycling limbal epithelial basal cells that can be preferentially stimulated to proliferate: Implications on epithelial stem cells. Cell 57, 201-209.

Daniel, E., Daudé, M., Kolotuev, I., Charish, K., Auld, V., and Le Borgne, R. (2018). Coordination of Septate Junctions Assembly and Completion of Cytokinesis in Proliferative Epithelial Tissues. Curr. Biol. 28, 1380-1391.e4.

Dantoft, W., Davis, M.M., Lindvall, J.M., Tang, X., Uvell, H., Junell, A., Beskow, A., and Engström, Y. (2013). The Oct1 homolog Nubbin is a repressor of NF-kB-dependent immune gene expression that increases the tolerance to gut microbiota. BMC Biology 11, 99.

Dasgupta, S., Gupta, K., Zhang, Y., Viasnoff, V., and Prost, J. (2018). Physics of lumen growth. PNAS 115, E4751-E4757.

Datta, A., Bryant, D.M., and Mostov, K.E. (2011). Molecular Regulation of Lumen Morphogenesis. Current Biology 21, R126-R136.

Deblandre, G.A., Wettstein, D.A., Koyano-Nakagawa, N., and Kintner, C. (1999). A two-step mechanism generates the spacing pattern of the ciliated cells in the skin of Xenopus embryos. Development $126,4715-4728$.

DeMaio, L., Tseng, W., Balverde, Z., Alvarez, J.R., Kim, K.-J., Kelley, D.G., Senior, R.M., Crandall, E.D., and Borok, Z. (2009). Characterization of mouse alveolar epithelial cell monolayers. American Journal of Physiology-Lung Cellular and Molecular Physiology 296, L1051-L1058.

Dietzl, G., Chen, D., Schnorrer, F., Su, K.-C., Barinova, Y., Fellner, M., Gasser, B., Kinsey, K., Oppel, S., Scheiblauer, S., et al. (2007). A genome-wide transgenic RNAi library for conditional gene inactivation in Drosophila. Nature 448, 151-156.

Doupé, D.P., Marshall, O.J., Dayton, H., Brand, A.H., and Perrimon, N. (2018). Drosophila intestinal stem and progenitor cells are major sources and regulators of homeostatic niche signals. PNAS $115,12218-12223$. 
Dumortier, J.G., Verge-Serandour, M.L., Tortorelli, A.F., Mielke, A., Plater, L. de, Turlier, H., and Maitre, J.-L. (2019). Hydraulic fracturing and active coarsening position the lumen of the mouse blastocyst. Science 365, 465-468.

Edwards, K.A., Demsky, M., Montague, R.A., Weymouth, N., and Kiehart, D.P. (1997). GFP-Moesin Illuminates Actin Cytoskeleton Dynamics in Living Tissue and Demonstrates Cell Shape Changes during Morphogenesis inDrosophila. Developmental Biology 191, 103-117.

Evans, M.J., and Moller, P.C. (1991). Biology of Airway Basal Cells. Experimental Lung Research 17, $513-531$.

Fleming, E.S., Zajac, M., Moschenross, D.M., Montrose, D.C., Rosenberg, D.W., Cowan, A.E., and Tirnauer, J.S. (2007). Planar spindle orientation and asymmetric cytokinesis in the mouse small intestine. J. Histochem. Cytochem. 55, 1173-1180.

Furuse, M., and Izumi, Y. (2017). Molecular dissection of smooth septate junctions: understanding their roles in arthropod physiology. Ann N Y Acad Sci 1397, 17-24.

Gilbert, T., and Rodriguez-Boulan, E. (1991). Induction of vacuolar apical compartments in the Caco2 intestinal epithelial cell line. Journal of Cell Science 100, 451-458.

Guillot, C., and Lecuit, T. (2013). Mechanics of epithelial tissue homeostasis and morphogenesis. Science $340,1185-1189$.

He, L., Binari, R., Huang, J., Falo-Sanjuan, J., and Perrimon, N. (2019). In vivo study of gene expression with an enhanced dual-color fluorescent transcriptional timer. ELife 8, e46181.

Izumi, Y., Motoishi, M., Furuse, K., and Furuse, M. (2016). A tetraspanin regulates septate junction formation in Drosophila midgut. J Cell Sci 129, 1155-1164.

Jiang, H., and Edgar, B.A. (2009). EGFR signaling regulates the proliferation of Drosophila adult midgut progenitors. Development 136, 483-493.

Jin, Y., Patel, P.H., Kohlmaier, A., Pavlovic, B., Zhang, C., and Edgar, B.A. (2017). Intestinal stem cell pool regulation in Drosophila. Stem Cell Reports 8, 1479-1487.

Jin, Z., Chen, J., Huang, H., Wang, J., Lv, J., Yu, M., Guo, X., Zhang, Y., Cai, T., and Xi, R. (2020). The Drosophila Ortholog of Mammalian Transcription Factor Sox9 Regulates Intestinal Homeostasis and Regeneration at an Appropriate Level. Cell Reports 31.

Jinguji, Y., and Ishikawa, H. (1992). Electron Microscopic Observations on the Maintenance of the Tight Junction during Cell Division in the Epithelium of the Mouse Small Intestine. Cell Struct Funct 17, 27-37.

Kapuria, S., Karpac, J., Biteau, B., Hwangbo, D., and Jasper, H. (2012). Notch-Mediated Suppression of TSC2 Expression Regulates Cell Differentiation in the Drosophila Intestinal Stem Cell Lineage. PLoS Genetics 8, e1003045.

Kizilyaprak, C., Longo, G., Daraspe, J., and Humbel, B.M. (2015). Investigation of resins suitable for the preparation of biological sample for 3-D electron microscopy. Journal of Structural Biology $189,135-146$.

Kolotuev, I. (2014). Positional Correlative Anatomy of Invertebrate Model Organisms Increases Efficiency of TEM Data Production. Microscopy and Microanalysis 20, 1392-1403.

Kolotuev, I., and Micheva, K.D. (2019). Can Correlative Microscopy Ever Be Easy? An Array Tomography Viewpoint. In Correlative Imaging, (John Wiley \& Sons, Ltd), pp. 81-98. 
Kolotuev, I., Schwab, Y., and Labouesse, M. (2010). A precise and rapid mapping protocol for correlative light and electron microscopy of small invertebrate organisms. Biology of the Cell 102, 121132.

Korzelius, J., Naumann, S.K., Loza-Coll, M.A., Chan, J.S., Dutta, D., Oberheim, J., Gläßer, C., Southall, T.D., Brand, A.H., Jones, D.L., et al. (2014). Escargot maintains stemness and suppresses differentiation in Drosophila intestinal stem cells. EMBO J 33, 2967-2982.

Koyama, L.A.J., Aranda-Díaz, A., Su, Y.-H., Balachandra, S., Martin, J.L., Ludington, W.B., Huang, K.C., and O'Brien, L.E. (2020). Bellymount enables longitudinal, intravital imaging of abdominal organs and the gut microbiota in adult Drosophila. PLOS Biology 18, e3000567.

Kremer, J.R., Mastronarde, D.N., and McIntosh, J.R. (1996). Computer Visualization of Three-Dimensional Image Data Using IMOD. Journal of Structural Biology 116, 71-76.

Lattner, J., Leng, W., Knust, E., Brankatschk, M., and Flores-Benitez, D. (2019). Crumbs organizes the transport machinery by regulating apical levels of PI(4,5)P2 in Drosophila. ELife 8, e50900.

Leblond, C.P. (1981). The life history of cells in renewing systems. Am. J. Anat. 160, 114-158.

Lee, T., and Luo, L. (1999). Mosaic analysis with a repressible cell marker for studies of gene function in neuronal morphogenesis. Neuron 22, 451-461.

Lee, W.-C., Beebe, K., Sudmeier, L., and Micchelli, C.A. (2009). Adenomatous polyposis coli regulates Drosophila intestinal stem cell proliferation. Development 136, 2255-2264.

Lemaitre, B., and Miguel-Aliaga, I. (2013). The Digestive Tract of Drosophila melanogaster. Annu Rev Genet 47, 377-404.

Leung, C.T., Coulombe, P.A., and Reed, R.R. (2007). Contribution of olfactory neural stem cells to tissue maintenance and regeneration. Nat Neurosci 10, 720-726.

Liang, J., Balachandra, S., Ngo, S., and O'Brien, L.E. (2017). Feedback regulation of steady-state epithelial turnover and organ size. Nature 548, 588-591.

Linden, S.K., Sutton, P., Karlsson, N.G., Korolik, V., and McGuckin, M.A. (2008). Mucins in the mucosal barrier to infection. Mucosal Immunology 1, 183-197.

Lowery, L.A., Rienzo, G.D., Gutzman, J.H., and Sive, H. (2009). Characterization and Classification of Zebrafish Brain Morphology Mutants. The Anatomical Record 292, 94-106.

Macara, I.G., Guyer, R., Richardson, G., Huo, Y., and Ahmed, S.M. (2014). Epithelial Homeostasis. Current Biology 24, R815-R825.

Madara, J.L. (1987). Intestinal absorptive cell tight junctions are linked to cytoskeleton. American Journal of Physiology-Cell Physiology 253, C171-C175.

Marianes, A., and Spradling, A.C. (2013). Physiological and stem cell compartmentalization within the Drosophila midgut. ELife 2, 155.

Martin, J.L., Sanders, E.N., Moreno-Roman, P., Jaramillo Koyama, L.A., Balachandra, S., Du, X., and O'Brien, L.E. (2018). Long-term live imaging of the Drosophila adult midgut reveals real-time dynamics of division, differentiation and loss. ELife 7, e36248.

McGuckin, M.A., Lindén, S.K., Sutton, P., and Florin, T.H. (2011). Mucin dynamics and enteric pathogens. Nature Reviews Microbiology 9, 265-278. 
McGuire, S.E., Le, P.T., Osborn, A.J., Matsumoto, K., and Davis, R.L. (2003). Spatiotemporal rescue of memory dysfunction in Drosophila. Science 302, 1765-1768.

McKinley, K.L., Stuurman, N., Royer, L.A., Schartner, C., Castillo-Azofeifa, D., Delling, M., Klein, O.D., and Vale, R.D. (2018). Cellular aspect ratio and cell division mechanics underlie the patterning of cell progeny in diverse mammalian epithelia. ELife 7, e36739.

McMahon, A., Supatto, W., Fraser, S.E., and Stathopoulos, A. (2008). Dynamic Analyses of Drosophila Gastrulation Provide Insights into Collective Cell Migration. Science 322, 1546-1550.

Meng, F.W., Rojas Villa, S.E., and Biteau, B. (2020). Sox100B Regulates Progenitor-Specific Gene Expression and Cell Differentiation in the Adult Drosophila Intestine. Stem Cell Reports 14, 226240.

Merzdorf, C.S., Chen, Y.-H., and Goodenough, D.A. (1998). Formation of Functional Tight Junctions in Xenopus Embryos. Developmental Biology 195, 187-203.

Micchelli, C.A., and Perrimon, N. (2006). Evidence that stem cells reside in the adult Drosophila midgut epithelium. Nature 439, 475-479.

Michael J. Evans, C.G.P., Laura S. Van Winkle, Michelle V. Fanucchi (2001). Cellular and Molecular Characteristics of Basal Cells in Airway Epithelium. Experimental Lung Research 27, 401-415.

de Navascués, J., Perdigoto, C.N., Bian, Y., Schneider, M.H., Bardin, A.J., Martínez-Arias, A., and Simons, B.D. (2012). Drosophila midgut homeostasis involves neutral competition between symmetrically dividing intestinal stem cells. EMBO J 31, 2473-2485.

Nie, Y., Li, Q., Amcheslavsky, A., Duhart, J.C., Veraksa, A., Stocker, H., Raftery, L.A., and Ip, Y.T. (2015). Bunched and Madm Function Downstream of Tuberous Sclerosis Complex to Regulate the Growth of Intestinal Stem Cells in Drosophila. Stem Cell Rev and Rep 11, 813-825.

O'Brien, L.E. (2013). Regional specificity in the Drosophila midgut: setting boundaries with stem cells. Cell Stem Cell 13, 375-376.

O'Brien, L.E., Zegers, M.M.P., and Mostov, K.E. (2002). Opinion: Building epithelial architecture: insights from three-dimensional culture models. Nat Rev Mol Cell Biol 3, 531-537.

O'Brien, L.E., Soliman, S.S., Li, X., and Bilder, D. (2011). Altered modes of stem cell division drive adaptive intestinal growth. Cell 147, 603-614.

Ohlstein, B., and Spradling, A. (2006). The adult Drosophila posterior midgut is maintained by pluripotent stem cells. Nature 439, 470-474.

Ohlstein, B., and Spradling, A. (2007). Multipotent Drosophila intestinal stem cells specify daughter cell fates by differential Notch signaling. Science 315, 988-992.

Overeem, A.W., Bryant, D.M., and van IJzendoorn, S.C.D. (2015). Mechanisms of apical-basal axis orientation and epithelial lumen positioning. Trends in Cell Biology 25, 476-485.

Parslow, A., Cardona, A., and Bryson-Richardson, R.J. (2014). Sample drift correction following 4D confocal time-lapse imaging. J Vis Exp e51086-e51086.

Pellettieri, J., and Alvarado, A.S. (2007). Cell turnover and adult tissue homeostasis: From humans to planarians. Annu Rev Genet 41, 83-105. 
Perdigoto, C.N., Schweisguth, F., and Bardin, A.J. (2011). Distinct levels of Notch activity for commitment and terminal differentiation of stem cells in the adult fly intestine. Development 138, 4585-4595.

Quan, Z., Sun, P., Lin, G., and Xi, R. (2013). TSC1/ 2 regulates intestinal stem cell maintenance and lineage differentiation through Rheb-TORC1-S6K but independently of nutritional status or Notch regulation. J Cell Sci 126, 3884-3892.

Rock, J.R., Onaitis, M.W., Rawlins, E.L., Lu, Y., Clark, C.P., Xue, Y., Randell, S.H., and Hogan, B.L.M. (2009). Basal cells as stem cells of the mouse trachea and human airway epithelium. Proceedings of the National Academy of Sciences 106, 12771-12775.

Ruiz-Herrero, T., Alessandri, K., Gurchenkov, B.V., Nassoy, P., and Mahadevan, L. (2017). Organ size control via hydraulically gated oscillations. Development 144, 4422-4427.

Schindelin, J., Arganda-Carreras, I., Frise, E., Kaynig, V., Longair, M., Pietzsch, T., Preibisch, S., Rueden, C., Saalfeld, S., Schmid, B., et al. (2012). Fiji: an open-source platform for biological-image analysis. Nat Methods 9, 676-682.

Sedzinski, J., Hannezo, E., Tu, F., Biro, M., and Wallingford, J.B. (2016). Emergence of an Apical Epithelial Cell Surface In Vivo. Developmental Cell 36, 24-35.

Sedzinski, J., Hannezo, E., Tu, F., Biro, M., and Wallingford, J.B. (2017). RhoA regulates actin network dynamics during apical surface emergence in multiciliated epithelial cells. J Cell Sci 130, 420-428.

Sekiya, K., Futaesaku, Y., and Nakase, Y. (1988). Electron microscopic observations on tracheal epithelia of mice infected with Bordetella bronchiseptica. Microbiol. Immunol. 32, 461-472.

Sigurbjörnsdóttir, S., Mathew, R., and Leptin, M. (2014). Molecular mechanisms of de novo lumen formation. Nat Rev Mol Cell Biol 15, 665-676.

Stubbs, J.L., Davidson, L., Keller, R., and Kintner, C. (2006). Radial intercalation of ciliated cells during Xenopus skin development. Development 133, 2507-2515.

Taniguchi, K., Shao, Y., Townshend, R.F., Cortez, C.L., Harris, C.E., Meshinchi, S., Kalantry, S., Fu, J., O'Shea, K.S., and Gumucio, D.L. (2017). An apicosome initiates self-organizing morphogenesis of human pluripotent stem cells. J Cell Biol 216, 3981-3990.

Tsujimura, A., Koikawa, Y., Salm, S., Takao, T., Coetzee, S., Moscatelli, D., Shapiro, E., Lepor, H., Sun, T.-T., and Wilson, E.L. (2002). Proximal location of mouse prostate epithelial stem cells : a model of prostatic homeostasis. Journal of Cell Biology 157, 1257-1265.

Varadarajan, S., Stephenson, R.E., and Miller, A.L. (2019). Multiscale dynamics of tight junction remodeling. J Cell Sci 132.

Vasquez, C.G., Vachharajani, V.T., Garzon-Coral, C., and Dunn, A.R. (2021). Physical basis for the determination of lumen shape in a simple epithelium. Nature Communications.

Vega-Salas, D.E. (1988). Exocytosis of vacuolar apical compartment (VAC): a cell-cell contact controlled mechanism for the establishment of the apical plasma membrane domain in epithelial cells. The Journal of Cell Biology 107, 1717-1728.

Viitanen, A., Gullmets, J., Morikka, J., Katajisto, P., Mattila, J., and Hietakangas, V. (2021). An image analysis method for regionally defined cellular phenotyping of the Drosophila midgut. Cell Reports Methods 100059. 
Voiculescu, O., Bertocchini, F., Wolpert, L., Keller, R.E., and Stern, C.D. (2007). The amniote primitive streak is defined by epithelial cell intercalation before gastrulation. Nature 449, 1049-1052.

Walck-Shannon, E., and Hardin, J. (2014). Cell intercalation from top to bottom. Nat Rev Mol Cell Biol 15, 34-48.

Wang, A.Z., Ojakian, G.K., and Nelson, W.J. (1990). Steps in the morphogenesis of a polarized epithelium. I. Uncoupling the roles of cell-cell and cell-substratum contact in establishing plasma membrane polarity in multicellular epithelial (MDCK) cysts. Journal of Cell Science 95 ( Pt 1), 137-151.

Xiang, J., Bandura, J., Zhang, P., Jin, Y., Reuter, H., and Edgar, B.A. (2017). EGFR-dependent TORindependent endocycles support Drosophila gut epithelial regeneration. Nat Commun 8, 15125.

Xu, C., Tang, H.-W., Hung, R.-J., Hu, Y., Ni, X., Housden, B.E., and Perrimon, N. (2019). The Septate Junction Protein Tsp2A Restricts Intestinal Stem Cell Activity via Endocytic Regulation of aPKC and Hippo Signaling. Cell Rep 26, 670-688.e6.

Yanagihashi, Y., Usui, T., Izumi, Y., Yonemura, S., Sumida, M., Tsukita, S., Uemura, T., and Furuse, M. (2012). A novel smooth septate junction-associated membrane protein, Snakeskin, is required for intestinal barrier function in Drosophila. Journal of Cell Science 125, 1980-1990.

Yang, Q., Xue, S.-L., Chan, C.J., Rempfler, M., Vischi, D., Maurer-Gutierrez, F., Hiiragi, T., Hannezo, E., and Liberali, P. (2021). Cell fate coordinates mechano-osmotic forces in intestinal crypt formation. Nat Cell Biol 23, 733-744.

Yu, H.H., and Zallen, J.A. (2020). Abl and Canoe/ Afadin mediate mechanotransduction at tricellular junctions. Science 370. 
bioRxiv preprint doi: https://doi.org/10.1101/2021.09.19.457819; this version posted September 19, 2021. The copyright holder for this preprint

(which was not certified by peer review) is the author/funder, who has granted bioRxiv a license to display the preprint in perpetuity. It is made available under aCC-BY-NC-ND 4.0 International license.

\section{FIGURES and CAPTIONS}

\section{Figure 1}
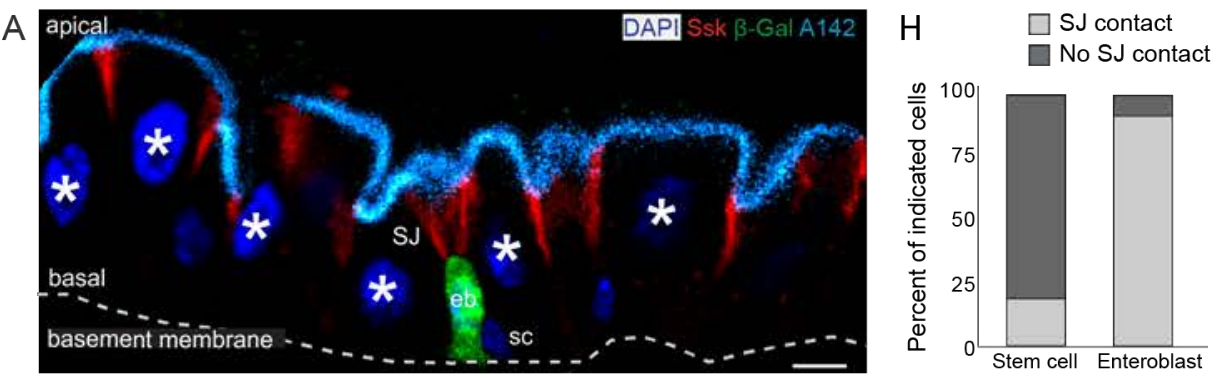

B
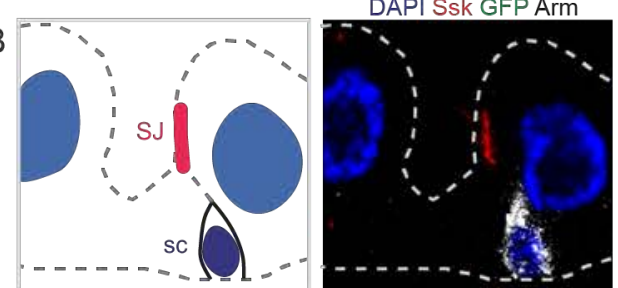

DAPI Ssk Esg

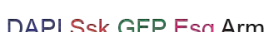

C
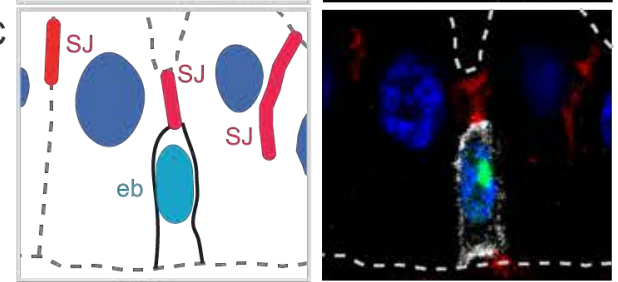

D
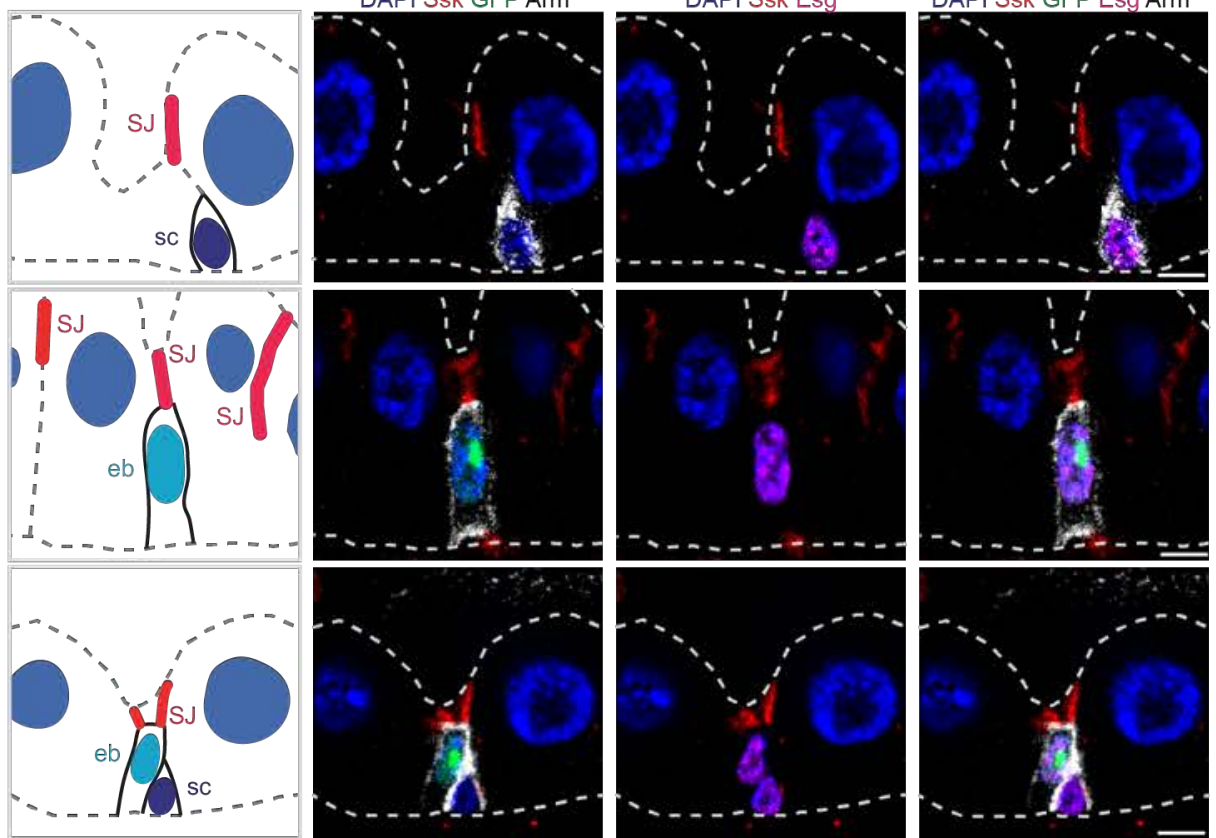

DAPI Tsp2A GFP Arm

E

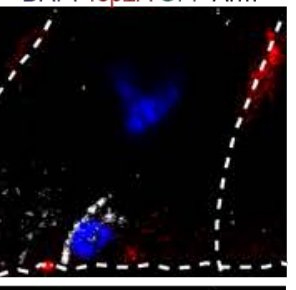

DAPI Tsp2A Esg

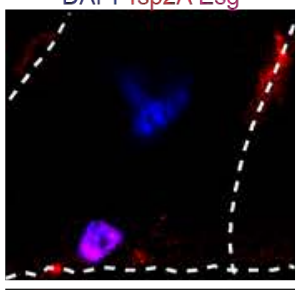

DAPI Tsp2A GFP Esg Arm
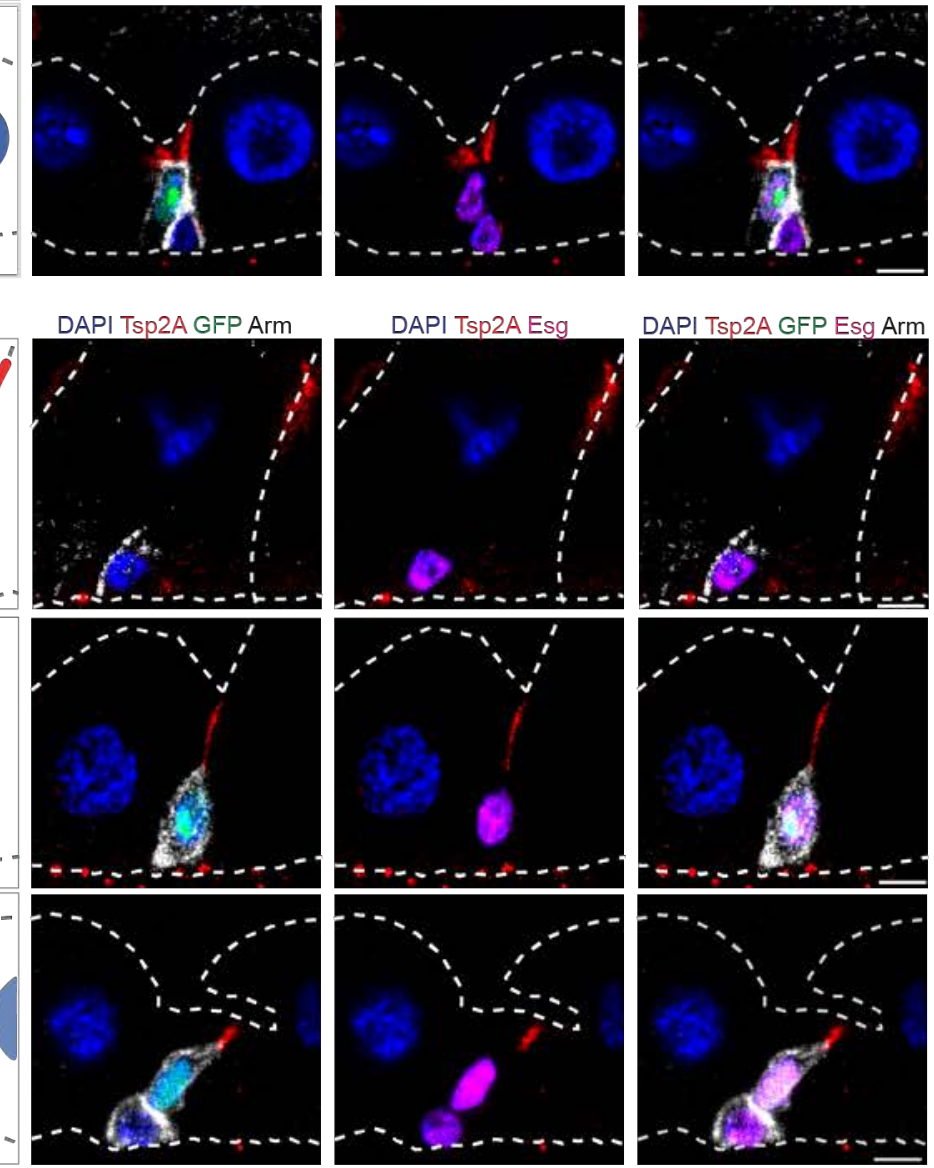

$\mathrm{F}$
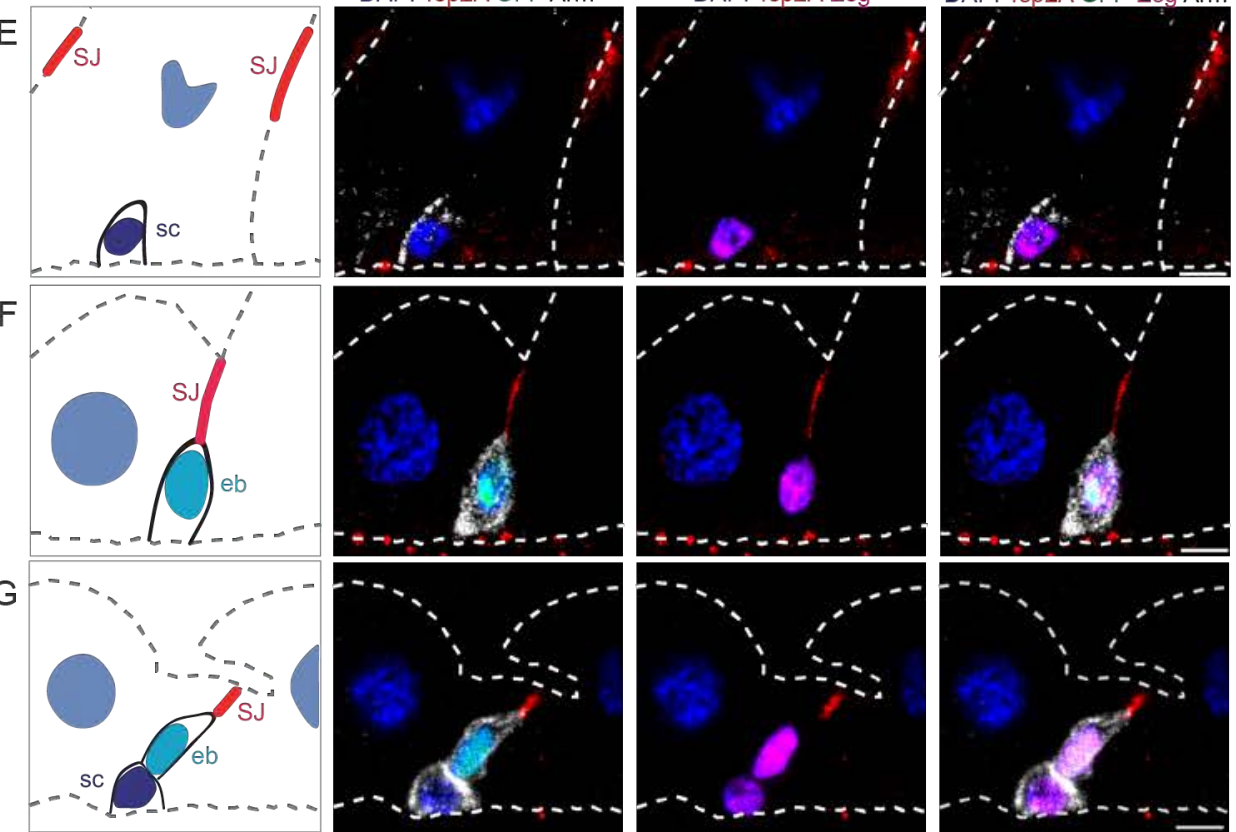
Figure 1. The apical tip of a differentiating enteroblast contacts the SJ of its neighbor enterocytes.

A) Architecture and stem cell lineage of the fly midgut epithelium, shown in cross-sectional view with apical lumenal surface (cyan, Mdu::GFP - see Fig. S2) at top and basal surface (dotted line, basement membrane) at bottom. Three cell types make up the absorptive lineage: (1) Stem cells (sc) are basally localized, diploid cells that do not express $S u(H)$-lacZ. (2) Enteroblasts (eb) are terminally committed stem cell progeny. Enteroblasts are transitioning from stem-like cells to enterocytes and are marked by $S u(H)$-lac $Z$ expression (green, $\beta$-Gal). Stem cells and enteroblasts often appear in pairs. (3) Mature enterocytes are large cells with polyploid nuclei (asterisks). Septate junctions (SJ; red, Snakeskin) appear at the apico-lateral borders of enterocytes.

B-G) Stem cells do not overlap with SJs, while the apical tips of enteroblasts contact the basal termini of enterocyte-enterocyte SJs. Cartoons (left column) and channel overlays from 5-channel multi-photon laser microscopy of esgGAL4, UAS-his2b::CFP; $S u(H)$-GFP::nls midguts immunostained for SJ components Ssk (red, B-D) or Tsp2a (red, E-G) and for the stem cell/enteroblast marker Arm (white; cortical). esg-driven His2b::CFP is shown in magenta, $S u(H)$-driven GFP::nls in green and nuclei (DAPI) in blue. Lumenal epithelial surface and basement membrane are indicated by dotted gray lines. Stem cells (sc) are His:: $\mathrm{CFP}^{+}$, Arm ${ }^{+}$, GFP::nls ${ }^{-}$cells in Panels B, D, E, G; enteroblasts (eb) are His:::CFP ${ }^{+}, \mathrm{Arm}^{+}, \mathrm{GFP}:: \mathrm{nl}^{+}$cells in Panels C, D, F, G. Panels D and G show stem cell-enteroblast pairs. All scale bars: $5 \mu \mathrm{m}$. Images are projections of short confocal stacks. Full genotypes in Table 1.

H) Quantitation of B-G. Most enteroblasts (92\%), but few stem cells (19\%) contact the epithelial septate junction network. $\mathrm{N}=5$ midguts; $\mathrm{n}=119$ stem cells and 125 enteroblasts. 
bioRxiv preprint doi: https://doi.org/10.1101/2021.09.19.457819; this version posted September 19, 2021. The copyright holder for this preprint

(which was not certified by peer review) is the author/funder, who has granted bioRxiv a license to display the preprint in perpetuity. It is made available under aCC-BY-NC-ND 4.0 International license.

\section{Figure 2}
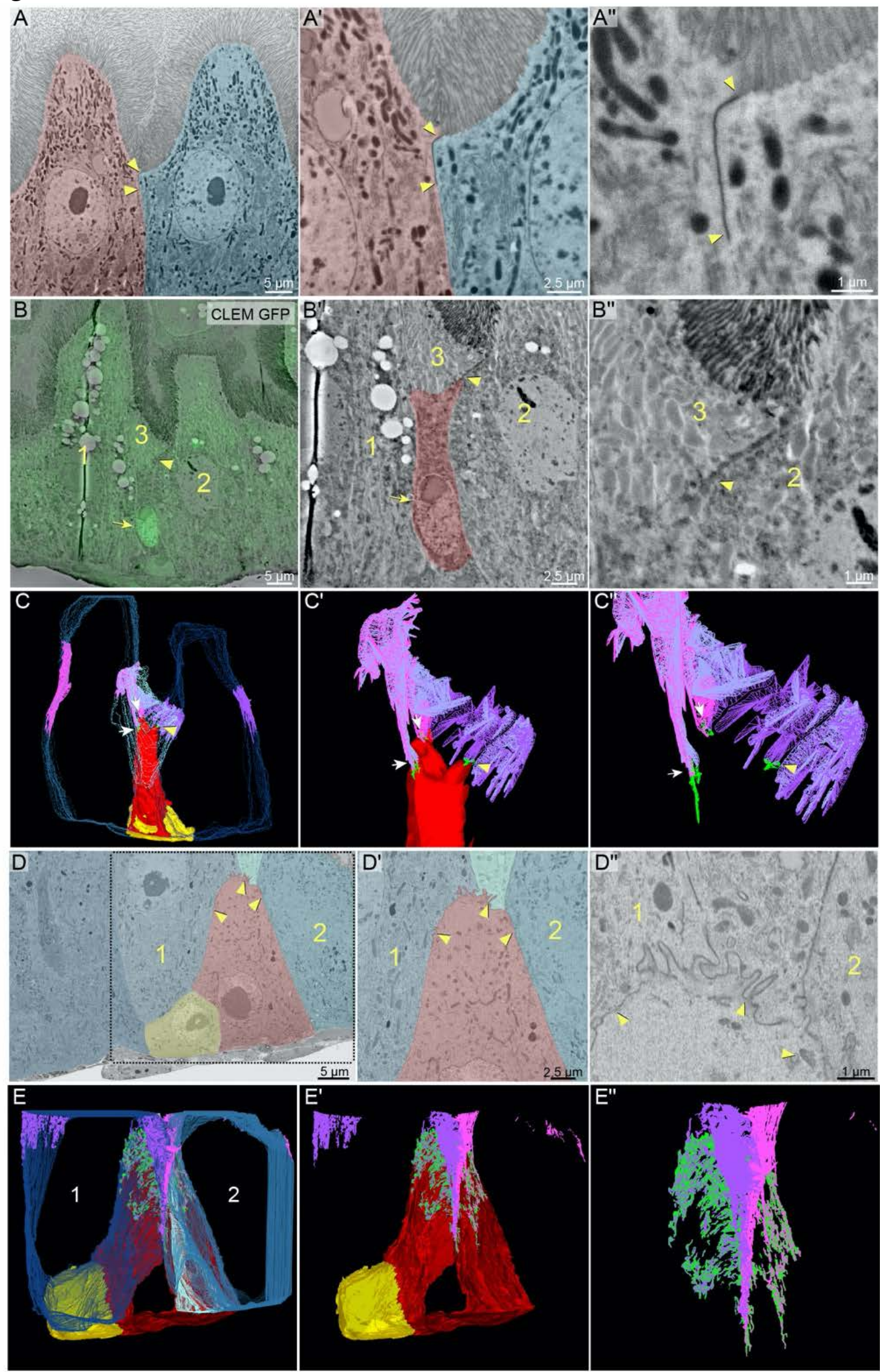
Figure 2. The differentiating enteroblast's apex initiates a new $\mathrm{SJ}$ at the basal-most edge of mature enterocyte SJs and triggers their remodeling to form a basally extended SJ sheet.

(A) Mature enterocytes localize SJs to the boundary between lumen-facing, brush border apical membranes and lateral membranes. SEM shows two mature enterocytes (pink and blue pseudocolor). Apical membranes are identifiable as microvilli-rich brush borders. An electron-dense SJ (arrowheads) fuses together the enterocytes' lateral membranes at a site directly adjacent to these brush borders. Zoomed-in views of SJ in A are shown in $\mathrm{A}^{\prime}$ and $\mathrm{A}^{\prime \prime}$.

(B-C) The apex (apical-most tip) of a young, $\mathrm{Su}(\mathrm{H})^{+}$enteroblast initiates $\mathrm{SJ}$ adhesions at the basal edge of enterocyte SJs. CLEM overlay (B) identifies a Su(H)-GFP::nls ${ }^{+}$enteroblast (arrow) in a FIB- SEM section. Zoomed-in images of the enteroblast ( $\mathrm{B}^{\prime}$, red pseudocolor) and of the enteroblast apex (B") show a nascent SJ (arrowheads in B-B") between the enteroblast and neighbor enterocytes 2 and 3 (labelled). (Only a small wedge of enterocyte 3 is visible in this section.) See Fig. S1. Volumetric rendering (C) of 30 FIB-SEM sections, including the section in B, reveals that each of apex's three fingers forms a SJ (arrows and arrowhead; arrowhead points to the same SJ in B and C) with each of three neighbor enterocytes. Cells and SJs are color coded: enteroblast, red; enteroblast SJs, green; enterocytes 1-3, blue; enterocyte $1 \mathrm{SJs}$, magenta; enterocyte $2 \mathrm{SJ}$, light purple; enterocyte 3 SJs, light blue; stem cell, yellow. Zoomed-in views of the enteroblast apex and associated SJs are shown in $C^{\prime}$ and $C^{\prime \prime}$. See Video 1.

(D-E) An older enteroblast is blanketed by the broad, basally extended SJ it has formed with the lateral membranes of neighboring mature cells. A FIB-SEM section (D) shows an enteroblast (red pseudocolor), two mature enterocytes (cells 1 and 2; blue pseudocolor), a mature enteroendocrine cell (cell 3; light blue pseudocolor), and a presumptive stem cell (yellow pseudocolor). The apical third of the enteroblast has formed an SJ (arrowheads in D-D") with the lateral membranes of the mature cells. Zoomed-in views of the enteroblast apex are shown in $\mathrm{D}^{\prime}$ and $\mathrm{D}^{\prime \prime}$. Volumetric rendering (E) of 413 FIB-SEM sections, including the section in D, reveals basal extensions of both enteroblast-enterocyte SJs and associated enterocyte-enterocyte SJs. View of the SJ with only the enteroblast and stem cell is shown in E'. Zoomed-in view of the SJ alone is shown in E'. Cells and SJs are color coded: enteroblast, red; enteroblast SJ, green; enterocytes 1 and 2, blue; enterocyte $1 \mathrm{SJ}$, lavender; enterocyte 2 SJ, magenta; enteroendocrine cell, light blue; stem cell, yellow. See Video 2. Full genotypes in Table 1. 


\section{Figure S1 (related to Figure 2C)}

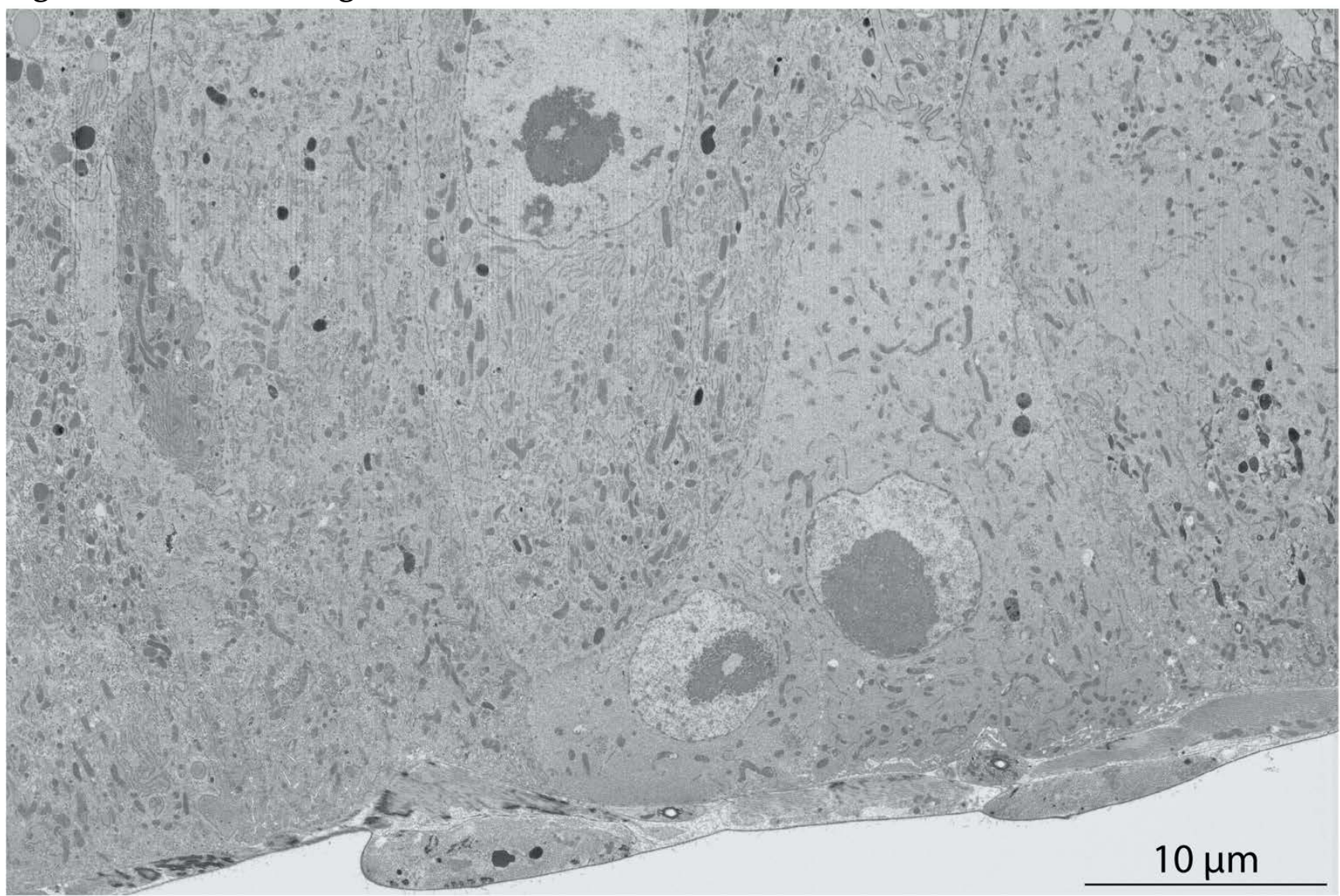

Figure S1 (related to Figure 2D). High resolution view of FIB-SEM section shown in Figure 2D.

$30 \mathrm{~nm}$-thick sections were cut with a gallium ion beam at $30 \mathrm{keV}$ and $770 \mathrm{pA}$. Images were taken with the electron beam at $2 \mathrm{keV}, 0.8 \mathrm{nA}, 2 \mathrm{~mm}$ working distance, $20 \mu$ s dwell time, $6144 \times 4096$ pixel frame size. Pixel size 9.7nm. Full genotypes in Table 1.

Video 1 (related to Figure 2C). Three-dimensional ultrastructure of nascent SJ between $\mathrm{Su}(\mathrm{H})-\mathrm{GFP}:: n l s^{+}$enteroblast and mature enterocytes.

Tomographic reconstruction of 30 serial images, including the image in Fig. 2B, from midgut expressing $S u(H)-G F P:: n l s$. Serial sections were cut with a gallium ion beam at $10 \mathrm{kV}$, spot size 5, pixel frame size 4096x4096, pixel dwell time $10 \mu$ s. Pixel size $8.7 \mathrm{~nm}$. Slice thickness, $150 \mathrm{~nm}$. Volume of reconstruction, 35.6um x 35.6um x $4.5 \mu \mathrm{m}$. Full genotypes in Table 1 .

\section{Video 2 (related to Figure 2E). Three-dimensional ultrastructure of SJ 'cap' between enteroblast and mature cells.}

Tomographic reconstruction of 413 serial FIB-SEM images, including the image shown in Figs. 2C and S1. Volume of reconstruction, $55 \mu \mathrm{m} \times 36.6 \mu \mathrm{m} \times 12.3 \mu \mathrm{m}$. Slice thickness, 30nm. Full genotypes in Table 1. 
bioRxiv preprint doi: https://doi.org/10.1101/2021.09.19.457819; this version posted September 19, 2021. The copyright holder for this preprint (which was not certified by peer review) is the author/funder, who has granted bioRxiv a license to display the preprint in perpetuity. It is made available under aCC-BY-NC-ND 4.0 International license.

Figure 3

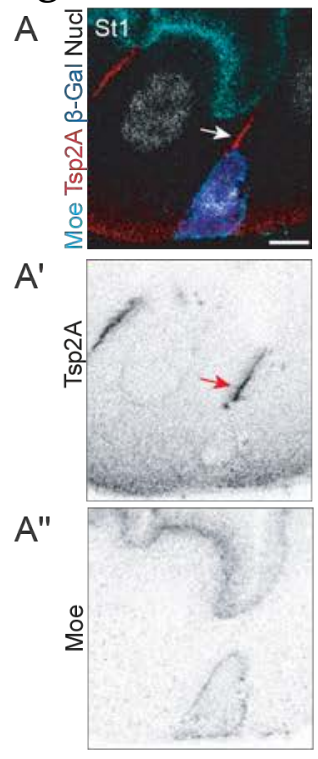

B

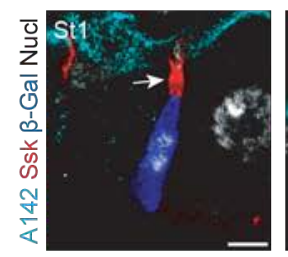

B'

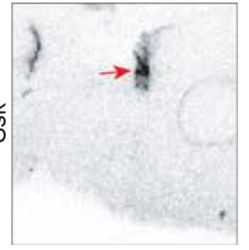

B"

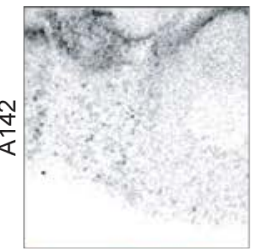

C

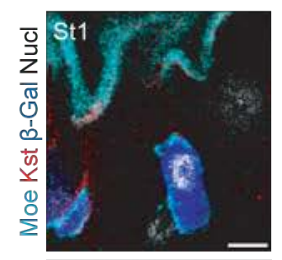

$C^{\prime}$

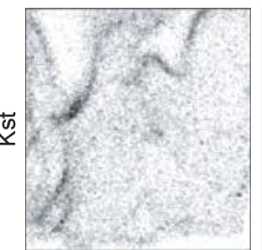

C"

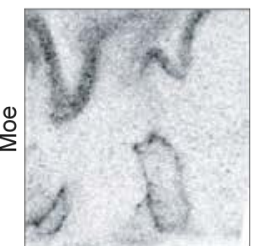

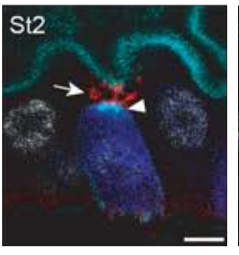
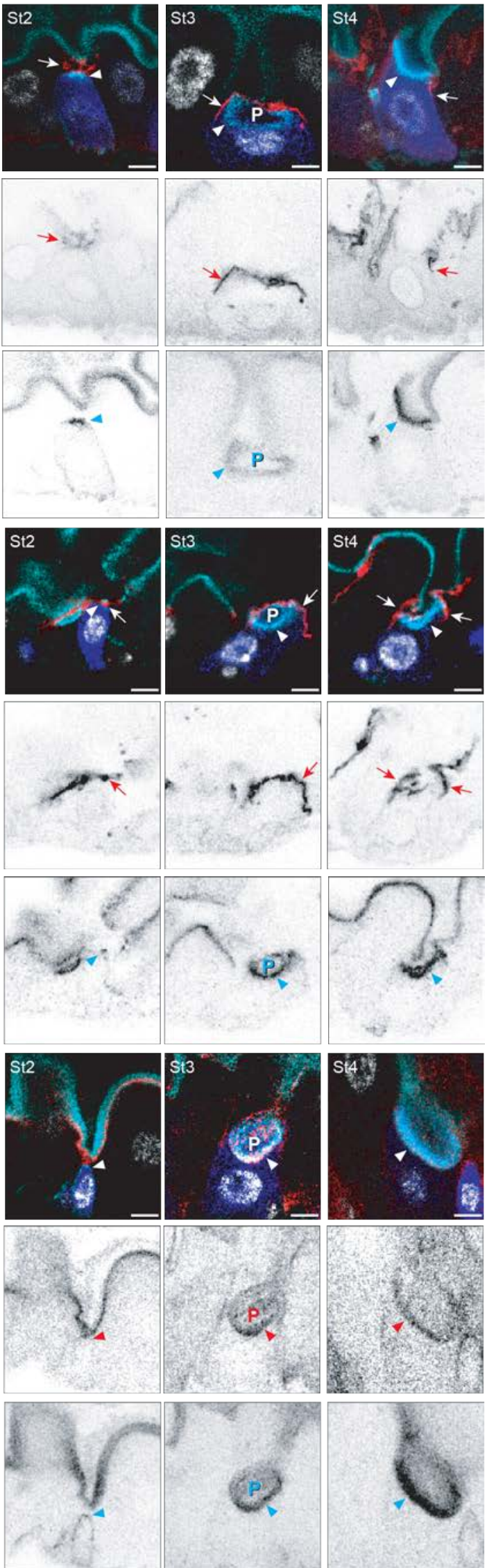
Figure 3. SJ and apical membrane morphology define four stages of barrier integration.

As differentiating cells integrate, they pass through four morphological stages that are distinguishable by SJ localization, polarization of apical markers, and cellular/nuclear size. SJs shown in red (A, Tsp2A; B, Ssk). Markers of enterocyte apical polarity shown in either cyan (A, C Moe::GFP; B, Mdu::GFP; c.f. Fig. S2) or red (C, Kst). Su(H)-lacZ in blue ( $\beta$-Gal, A-C). Nuclei (Nucl) shown in grayscale (A, Stage 1 and C - His2av::mRFP; A, Stages 2-4 and B - DAPI). Images are projections of short confocal stacks. Markers that are not fused to a fluorescent protein were visualized by immunostaining. All scale bars, $5 \mu \mathrm{m}$. $\beta$-gal channel shown in Fig. S3. Full genotypes in Table 1.

Stage 1 (St1). Enteroblast with initial SJ contact. The apex of a diploid enteroblast contacts the basal terminus of an enterocyte-enterocyte SJ (arrows). Apical markers are either non-polarized (Moe, Kst) or absent (Mdu).

Stage 2 (St2). Enteroblast with broadened SJ contacts and apical plaque. The enteroblast apex is partially covered by a widened enteroblast-enterocyte SJ (arrows). Some apical markers (Moe, $\mathrm{Mdu}$; arrowheads) become polarized to the apex, forming a plaque immediately basal to the SJ.

Stage 3 (St3). Pre-enterocyte with umbrella-like SJ and concave apical structure (PAAC). The apex of the cell is fully covered by a convex SJ (arrows). Apical markers outline a prominent concave structure (P; Pre-Assembled Apical Compartment, or PAAC) beneath the SJ. The PAAC fills the apex of the cell and is separate from the gut lumen (Video 3). Pre-enterocytes exhibit cytoplasmic/nuclear sizes intermediate between enteroblasts and mature enterocytes and low $\mathrm{Su}(H)$-driven $\beta$-gal signal (Fig. S3).

Stage 4 (St4). Pre-enterocyte integration becomes complete. The SJ circumscribes the cell, and the PAAC has coalesced with the gut lumen. The pre-enterocyte is still smaller than mature enterocytes and has a concave, rather than convex apical-lumenal surface, but the relative arrangement of its SJ, apical, and basolateral surfaces are topologically equivalent to a mature enterocyte. 


\section{Figure S2}

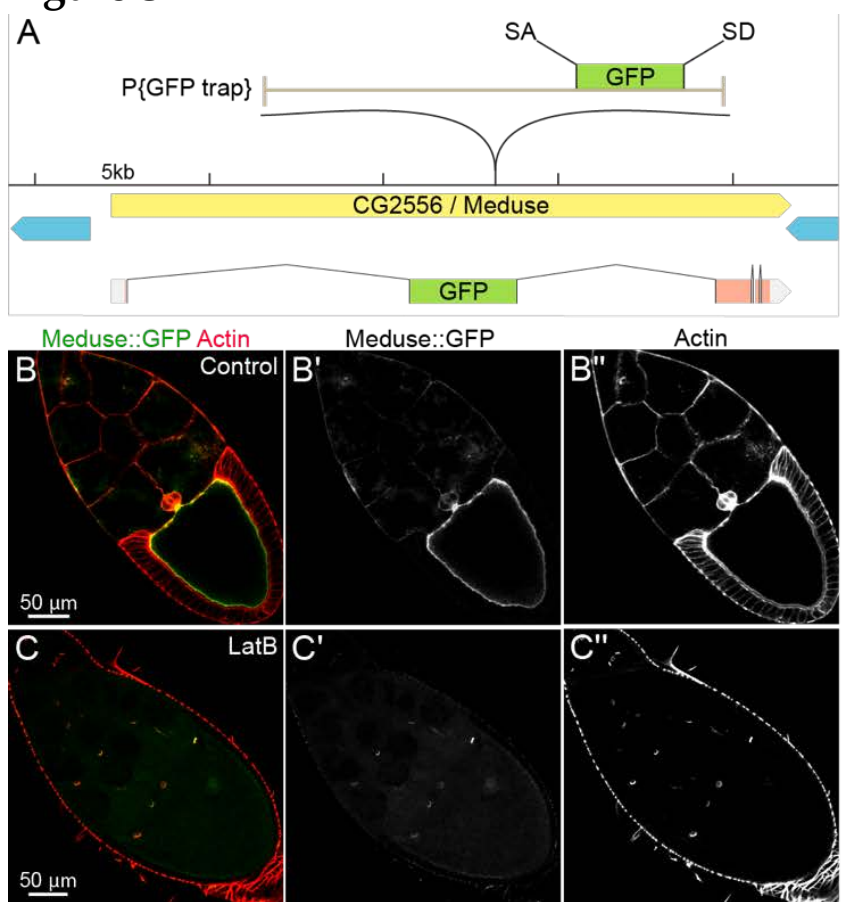

Figure S2 (related to Figure 3A-C). The A142 splice trap transposon is inserted into CG2556/Meduse, a novel protein that co-localizes with actin filaments.

(A) Genomic location of the splice trap transposon in the A142 line. The insertion was mapped by inverse PCR and genomic PCR to the large first intron of CG2556, approximately $10.6 \mathrm{~kb}$ downstream of the splice site in Exon 1. The transposon is inserted in the proper orientation to capture transcripts from CG2556, which would result in an N-terminal GFP tag on the nearly undisrupted protein (Exon 1 encodes only 7 amino acids including the initiator Met). The tentacular appearance of the fusion protein in oocytes prompted us to name the gene product Meduse (Mdu).

(B) Mdu::GFP co-localizes with cortical actin filaments in Stage 10 oocytes.

(C) Latrunculin B (LatB) treatment disrupts cortical actin filaments (red, Rhodaminphalloidin) in the oocyte and leads to abrogation of the oocyte Mdu::GFP signal. Note that LatB does not disrupt actin in ring canals; localization of Mdu::GFP to ring canals is visible in Panels $C$ and $C^{\prime}$. Full genotype in Table 1. 


\section{Figure S3 (related to Figure 3A-C)}

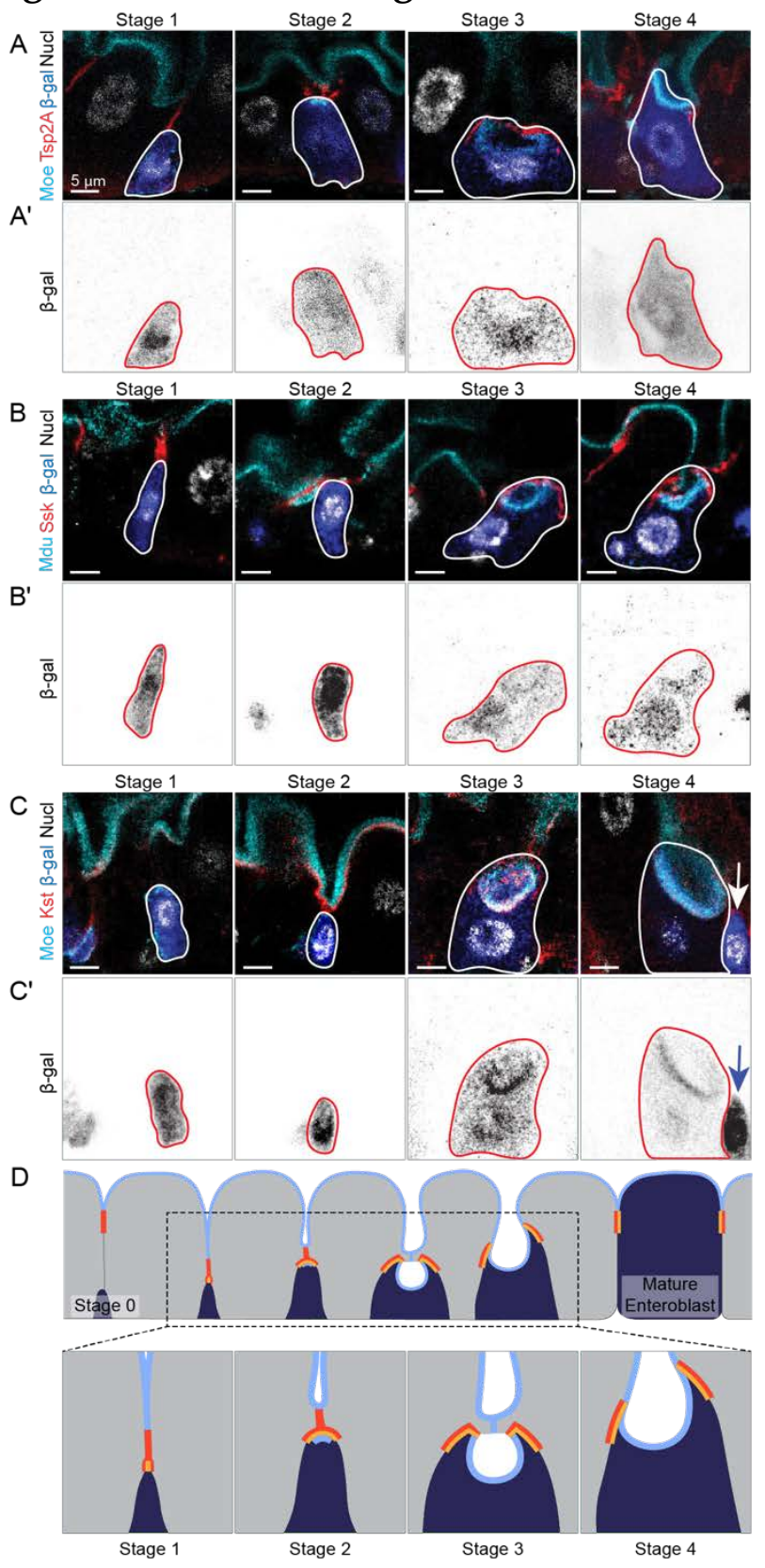

Figure S3 (related to Figure 3A-C). Immunostaining of $S u(H)$-driven $\beta$-galactosidase in integrating cells.

(A-C) The same four-channel images shown in Figure 3 are repeated above the corresponding, single-channel images of $\beta$-galactosidase immunostain. The presence of $\beta$-galactosidase in Stage 3 and Stage 4 cells demonstrates that these cells derived recently from enteroblasts. During acquisition of the Stage 3 and 4 images, the gain was increased compared to Stages 1 and 2 to visualize lower levels of $\beta$-galactosidase. Arrowheads in $C$ and $C^{\prime}$ point to a Stage 1 enteroblast next to the Stage 4 pre-enterocyte; at the higher gain necessary to visualize $\beta$ galactosidase in the Stage 4 pre-enterocyte, $\beta$-galactosidase intensity in the Stage 1 enteroblast is overexposed. Images are projections of short confocal stacks.

(D) Four-stage model of epithelial integration. A newborn enteroblast (Stage 0) forms SJ contacts between their apex and the basal edge of enterocyte-enterocyte SJs (Stage 1). The 
enteroblast-enterocyte SJ broadens, and apical markers accumulate at its cytoplasmic face (Stage 2). The enteroblast grows into a pre-enterocyte, characterized by the expansion of apical markers into a PAAC and broadening of the SJ into a diaphragm-like sheet (Stage 3). The PAAC's lumen fuses with the gut's central lumen, and SJs remodel to circumscribe the cell (Stage 4). Eventually, the concave lumenal-apical surface everts to form the convex apical surface that characterizes mature enterocytes. Enteroblast/pre-enterocyte SJs shown in orange, mature enterocyte SJs in red, and apical surface in light blue. Full genotypes in Table 1.

\section{Video 3 (related to Figure $3 \mathrm{~A}$ ). $360^{\circ}$ confocal reconstruction of a Stage 3 pre-enterocyte} shows that the PAAC's apical membrane is distinct from the gut's lumenal-apical surface.

Video shows reconstructed $360^{\circ}$ view of a Stage 3 pre-enterocyte, labeled by $\mathrm{Su}(\mathrm{H})$-driven $\beta$-galactosidase. The pre-enterocyte is surrounded by two mature enterocytes, and a pair of small, basal progenitor cells is visible between the pre-enterocyte and one of the mature enterocytes. The apical marker Moe::GFP outlines the lumenal-apical surface of the mature enterocytes, the PAAC in the pre-enterocyte, and the entire cortex of the progenitor cells. The SJ protein Tetraspanin2A forms a convex web that covers the apex of the pre-enterocyte. Nuclei are labelled with DAPI. Full genotype in Table 1. 


\section{Figure 4}

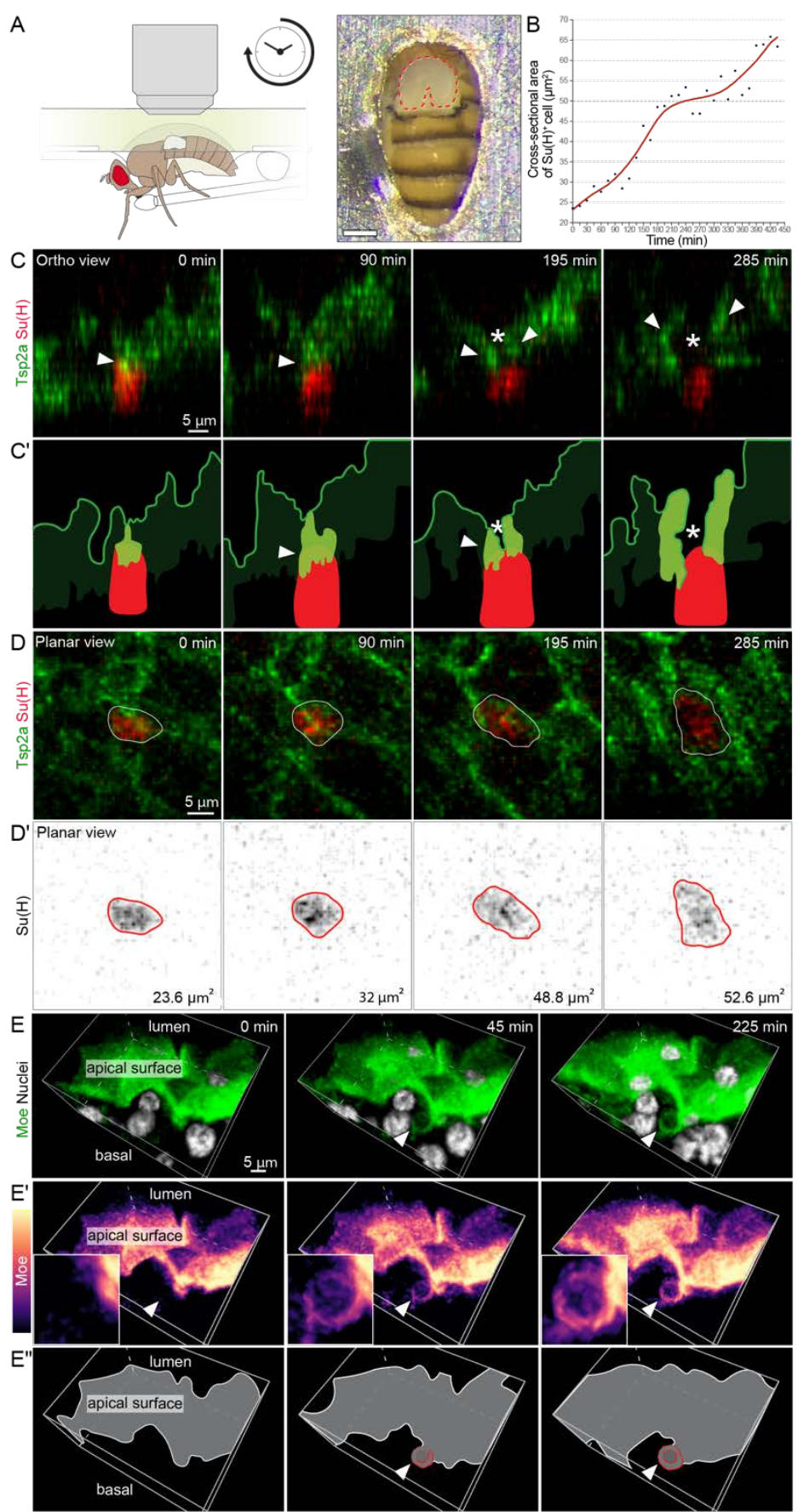

Figure 4: In vivo live imaging of SJ and PAAC dynamics supports the four-stage model of integration.

(A) Continuous time-lapse imaging of midguts in live, feeding Drosophila was performed through a window in the dorsal cuticle. Adapted from Martin, 2018.

(B) Cross-sectional area of the $S u(H)-m C_{\text {Cherry }}^{+}$cell shown in Panels C and D and in Video 4. The increase in area implies that this cell is actively differentiating from enteroblast to enterocyte.

(C-D) Live dynamics of SJ during enteroblast-enterocyte differentiation. Still frames are from a $7.25 \mathrm{~h}$ volumetric movie (Video 4) of a midgut expressing GS5961-tsp2A::GFP and Su(H)-mCherry. The cell analyzed in Panel B is shown in ortho view (C; apical at top) with corresponding line 
drawings $\left(\mathrm{C}^{\prime}\right)$. In ortho view, arrowheads point to the SJ associated with this cell and asterisk denotes estimated location of putative PAAC. The planar view is shown in (D); panels are projections of serial confocal images. Numbers in the lower right corner of panels in D' are crosssectional areas of the cell at the given time points. SJ morphogenesis over time is visible in the ortho view: Between $0 \mathrm{~min}$ and $90 \mathrm{~min}$, the SJ broadens over the cell's apex. At $195 \mathrm{~min}$, a hollow space (asterisk in C) develops along the SJ's apical-basal axis. Between 195 and 225 min, the hollow space widens; both the hollow space and its surrounding SJ elongate along the lateral edges of the nowlarger cell.

(E) Live imaging of PAAC development. Still frames from a $3.75 \mathrm{~h}$ volumetric movie (Video 5) of midgut expressing the apical marker moe::GFP (green in E; magma LUT in E') and the nuclear marker ubi-his2av::RFP (grayscale in E). Corresponding line drawings are in E". Arrowhead in E' points to the area of PAAC formation, which is also shown as a close-up in the inset. At 0 min, the lumenal-apical surface appears as a lumpy blanket overlying the gut cell nuclei; no PAAC is visible. By $45 \mathrm{~min}$, a putative PAAC has formed at the basal side of the lumenal-apical surface. By $225 \mathrm{~min}$, the PAAC has become deeper and brighter. Insets in E' show close-up views of the developing PAAC. Full genotypes for all panels in Table.

\section{Video 4 (related to Figure 4C and 4D). 7.5-hour continuous time-lapse of SJ dynamics during enteroblast-enterocyte differentiation.}

Windowmount imaging of midgut expressing GS5961-tsp2A::GFP and Su(H)-mCherry. Planar (top) and ortho (bottom) views of the same tissue volume are shown. In ortho view, the dotted white line indicates the basal surface of the differentiating cell. Arrowhead points to SJs (Tsp2A::GFP) associated with the differentiating, mCherry $^{+}$cell analyzed in Fig. 4B. Dynamics of the SJ in ortho view are consistent with the four-stage mechanism inferred from Fig. 3: Nascent contact (Stage 1), broadening and expansion over the cell apex (Stages 2-3), and central hollowing and lateral extension (Stage 4). Full genotype in Table 1.

\section{Video 5 (related to Figure 4E). 3.75-hour continuous time-lapse movie of PAAC development.}

Windowmount imaging of midgut expressing moesin::GFP and ubi-his2av::RFP. The Moesin::GFP channel (magma LUT) is shown without (left) and with (right) the His2av::RFP channel (grayscale). At $30 \mathrm{~min}$, a faint Moe::GFP-labelled structure (arrowhead) forms at the basal side of the gut's lumenal-apical surface. The concave shape of this structure is like PAACs in fixed samples (Fig. 3, Stage 3; Video 3). From 30-225 min, the putative PAAC deepens, and its GFP-labelled boundary brightens and thickens. Full genotype in Table 1. 
bioRxiv preprint doi: https://doi.org/10.1101/2021.09.19.457819; this version posted September 19,2021. The copyright holder for this preprint

(which was not certified by peer review) is the author/funder, who has granted bioRxiv a license to display the preprint in perpetuity. It is made available under aCC-BY-NC-ND 4.0 International license.

\section{Figure 5}
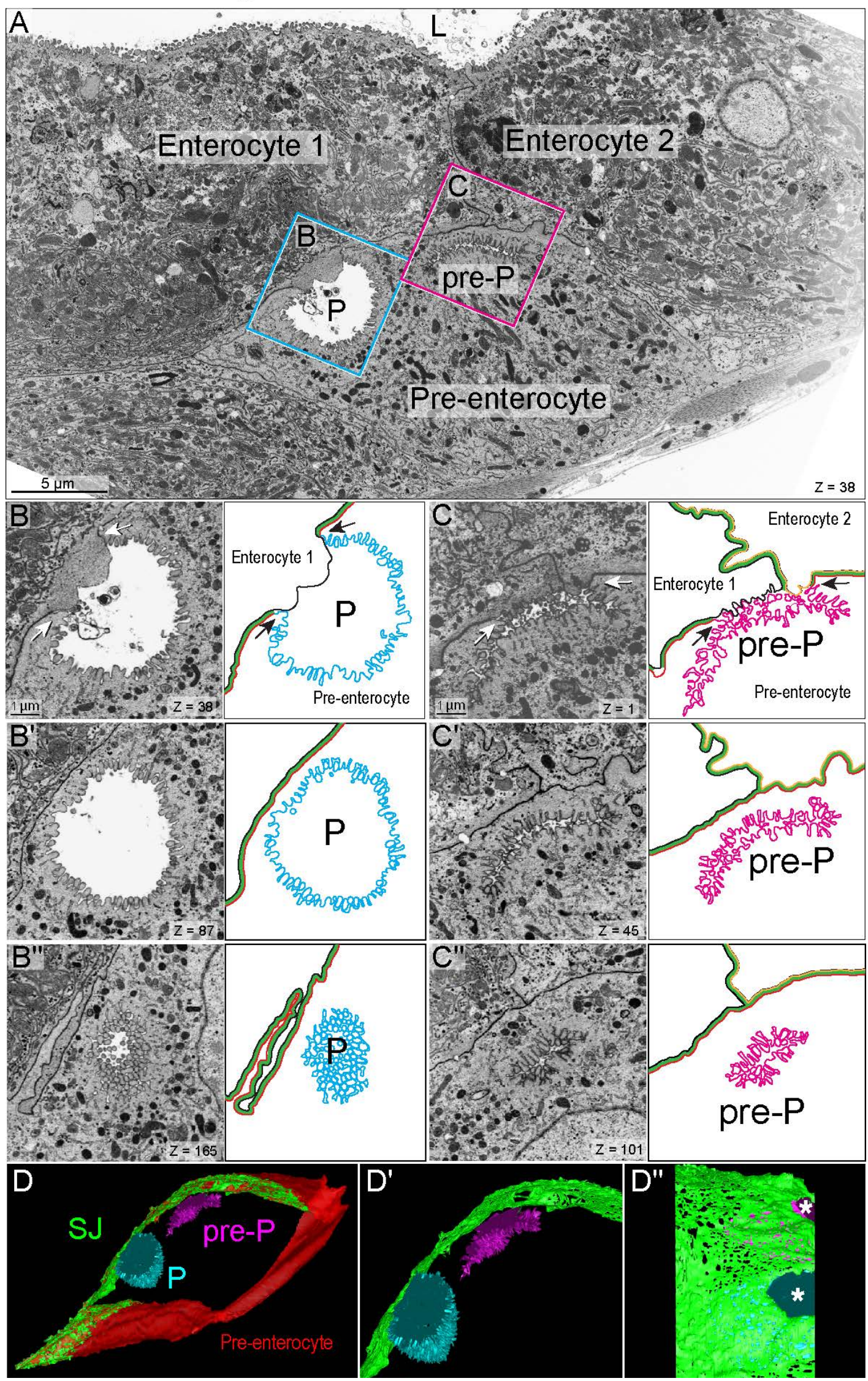


\section{Figure 5. PAACs are intercellular lumens with split apical-basolateral polarity.}

(A) One slice of a representative, 200-slice FIB-SEM tomographic series. Series captures two mature enterocytes that contact the gut's central lumen (L) and an underlying pre-enterocyte, which does not. An ellipsoid-shaped PAAC (P, cyan box) and an allantoid-shaped PAAC precursor (pre-P, magenta box) appear at the apex of the pre-enterocyte. See Figure $\mathrm{S} 4$.

(B) Close-up of the PAAC in cyan box in A. Three FIB-SEM sections are shown next to cartoon representations. P indicates the PAAC lumen. In cartoons, the apical membrane of the preenterocyte is cyan, the basolateral membrane of the pre-enterocyte is red, the basolateral plasma membrane of enterocyte 1 is black, and the $\mathrm{SJ}$ between the pre-enterocyte and enterocyte 1 is green. In $B$, a gap in the $\mathrm{SJ}$ reveals that the PAAC is an intercellular lumen between the apical preenterocyte membrane and the basolateral enterocyte membrane (split polarity). Arrows point to the three-way boundary between the pre-enterocyte apical membrane, the enterocyte basolateral membrane, and the pre-enterocyte basolateral membrane. In B' and B", the deep cytoplasmic invagination of the pre-enterocyte apical membrane forms most of the PAAC's lumenal volume.

(C) Close-up of the PAAC precursor in magenta box in A. pre-P indicates the PAAC precursor. In cartoons, the pre-enterocyte's apical membrane is magenta, the pre-enterocyte's basolateral membrane is red, the basolateral plasma membrane of enterocyte 1 is black, the basolateral membrane of enterocyte 2 is orange, and the SJ between the pre-enterocyte and enterocytes 1 and 2 is green. In C, a gap in the SJ reveals that the PAAC precursor is an intercellular lumen. Arrows point to two three-way boundaries between the pre-enterocyte apical membrane, the basolateral membrane of either enterocyte 1 or enterocyte 2, and the pre-enterocyte basolateral membrane. In $C^{\prime}$ and $C^{\prime \prime}$, the precursor's slender, allantoid-shaped lumen arises through invagination of the pre-enterocyte's convoluted apical membrane. In A-C, Z values in lower left of panels are slice numbers.

(D) Volumetric rendering of 200 FIB-SEM sections, including the section in A. Apical membranes of the pre-enterocyte are cyan (PAAC) and magenta (PAAC precursor), basolateral membrane of the pre-enterocyte is red, and $\mathrm{SJ}$ between the pre-enterocyte and mature enterocytes is in green. Zoomed-in panels show the PAAC, PAAC precursor, and SJ in a cutaway view (D') and a top-down view (D"). In D and D', the PAAC's ellipsoid shape and the precursor's allantoid shape are evident. In D", asterisks mark holes in the SJ resulting from separation of pre-enterocyte and enterocyte plasma membranes during PAAC formation. (Enterocyte membranes not shown.) See Video 6. Full genotype in Table 1. 


\section{Figure S4 (related to Figure 5A)}

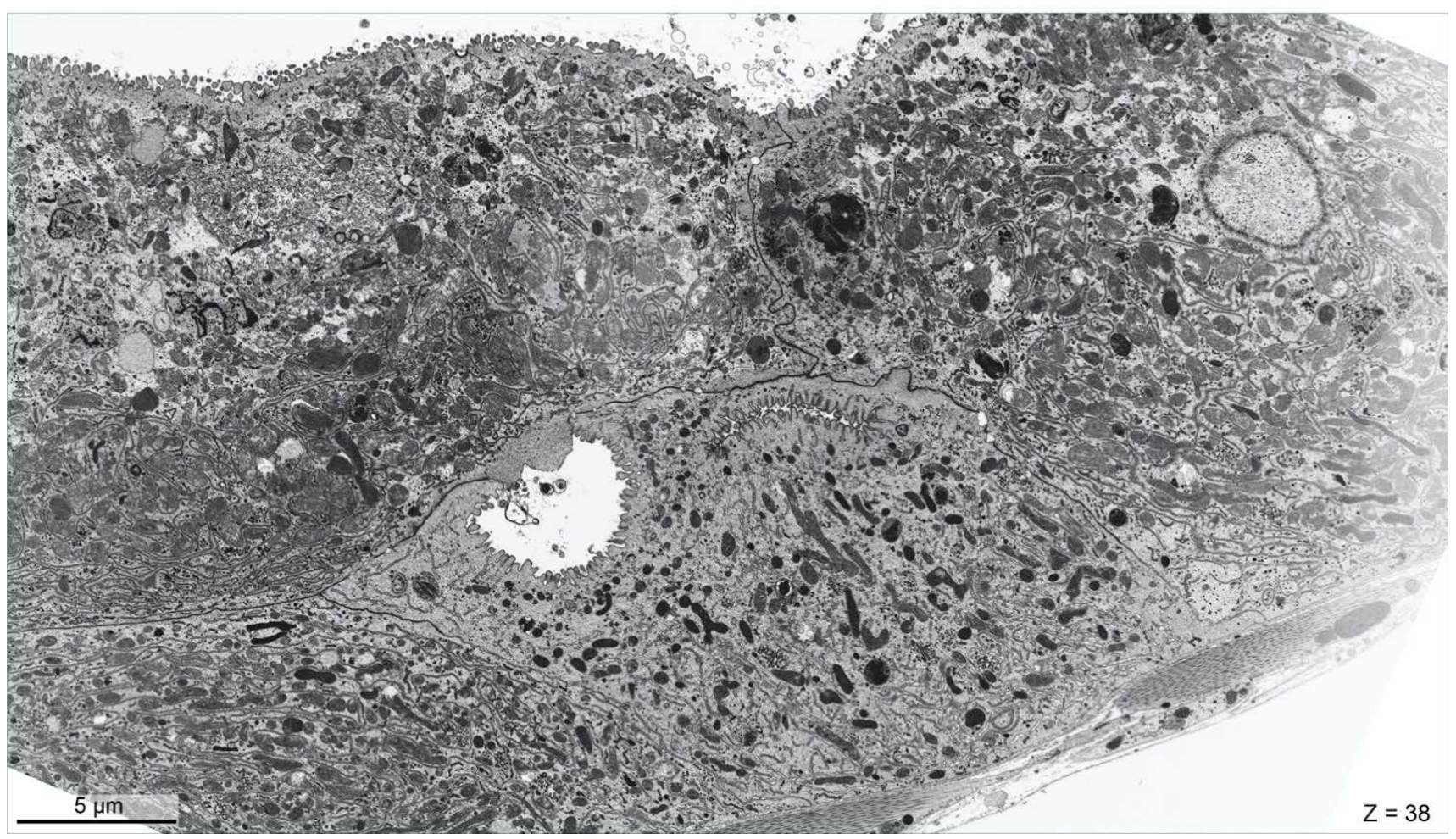

Figure S4 (related to Figure 5A). High resolution view of FIB-SEM section shown in Figure 4A.

$40 \mathrm{~nm}$-thick sections were cut with a gallium ion beam at $2 \mathrm{kV}, 0.8 \mathrm{nA}, 4.2 \mathrm{~mm}$ working distance, $5 \mu$ s dwell time, 6144x4096 frame size. Pixel size 9.7nm. Full genotype in Table 1.

Video 6 (related to Figure 5A-D). Three-dimensional ultrastructure of PAAC, PAAC precursor, and their associated pre-enterocyte.

Tomographic reconstruction of 200 serial FIB-SEM images, including a cropped version of the image shown in Figures $5 \mathrm{~A}$ and $S 4.360^{\circ}$ rotation reveals the ellipsoid and allantoid shapes of the PAAC and PAAC precursor, respectively, and reveals holes in the SJ in which the pre-enterocyte and enterocyte membranes have separated to form the intercellular lumens. Volume of reconstruction: $40.2 \mu \mathrm{m} \times 23.9 \mu \mathrm{m} \times 8 \mu \mathrm{m}$. Slice thickness, $40 \mathrm{~nm}$. Full genotype in Table 1 . 
Figure 6
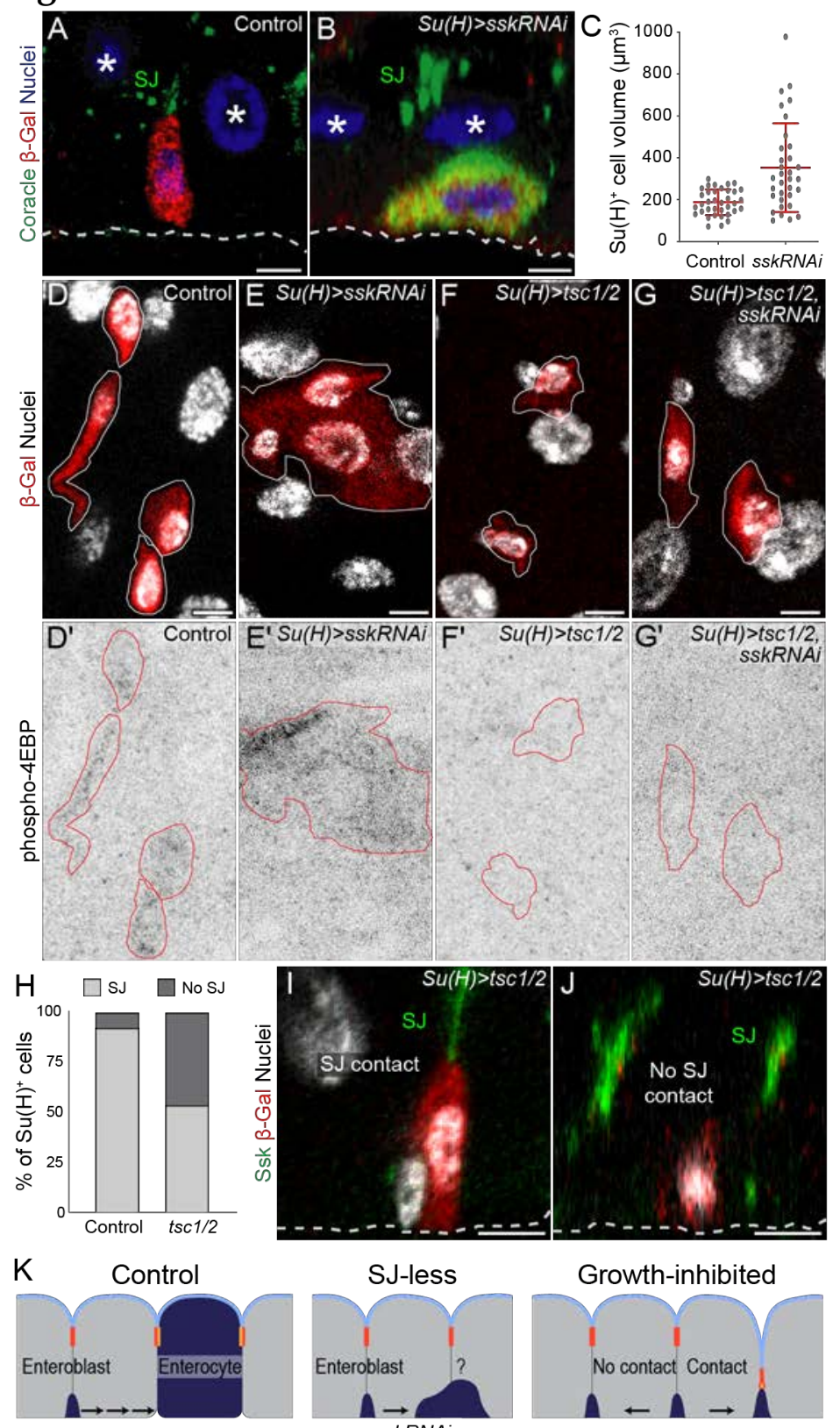

SJ-less

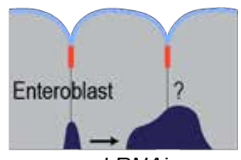

Growth-inhibited

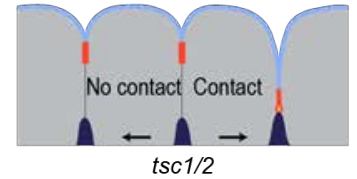

Figure 6. Cells must form SJs and grow in order to integrate.

(A-C) Blocking SJ formation prevents integration but not growth. (A) Cross-sectional view of control $S u(H)^{+}$cell (red, $S u(H)$-lacZ). The cell's apex has formed contacts with the basal tip of the SJ (green, Coracle) between neighbor enterocytes. (B) Cross-sectional view of $S u(H)^{t_{s}}>s s k R N A i$. The cell expresses $\mathrm{Su}(\mathrm{H})$-lacZ (red) and high levels of Coracle (green), which localizes to the cytoplasm. It does not contact either enterocyte-enterocyte SJs or the gut lumen. (C) Measurements of cytoplasmic volumes show that $S u(H)^{t_{s}}>$ sskRNAi cells become larger in size compared to control $S u(H)$ cells.

(D-G) Growth of $S u(H)^{t s}>s s k R N A i$ cells requires Tor pathway activation. Planar views of all midgut cell nuclei (grayscale, DAPI) and $S u(H)-l a c Z$ (red) are shown above corresponding images of phospho-4EBP immunostain (D'-G', inverted grayscale). $S u(H)$-lacZ-labelled cells are outlined in white (D-G) and red (D'-G'). Control $S u(H)$ cells (D) and $S u(H)^{t s}>$ sskRNAi (E) cells are phospho$4 \mathrm{EBP}^{+}\left(\mathrm{D}^{\prime}, \mathrm{E}^{\prime}\right)$. Tor-inhibited, $S u(H)^{t s}>t s c 1 / 2(\mathrm{~F})$ and $S u(H)^{t s}>\operatorname{ssk} R N A i, t s c 1 / 2(\mathrm{G})$ are not $\left(\mathrm{F}^{\prime}, \mathrm{G}^{\prime}\right)$. 
(H-J) Growth-inhibited enteroblasts arrest at initial stages of integration. The frequency with which $S u(H)^{t s}>t s c 1 / 2$ cells $(S u(H)-l a c Z$, red) contact the gut SJ network (Ssk, green) is reduced to $46 \%$ from the control frequency of $92 \%(\mathrm{H})$. Both $S u(H)^{t s}>t s c 1 / 2$ cells that contact SJs (I) and those that do not $(\mathrm{J})$ fail to reach the gut's lumenal surface. $\mathrm{N}=5$ control midguts (124 enteroblasts) and 3 $S u(H)>t s c 1 / 2$ midguts (166 enteroblasts). All scale bars, $5 \mu \mathrm{m}$. Full genotypes in Table 1.

(K) Cartoon summary: (Left) Control. Integration requires both cell growth and SJ formation. (Middle) Blocking SJ formation prevents integration but does not halt growth. (Right) Growth inhibition arrests cells in Stages 0-1 of integration. 


\section{Figure S5}
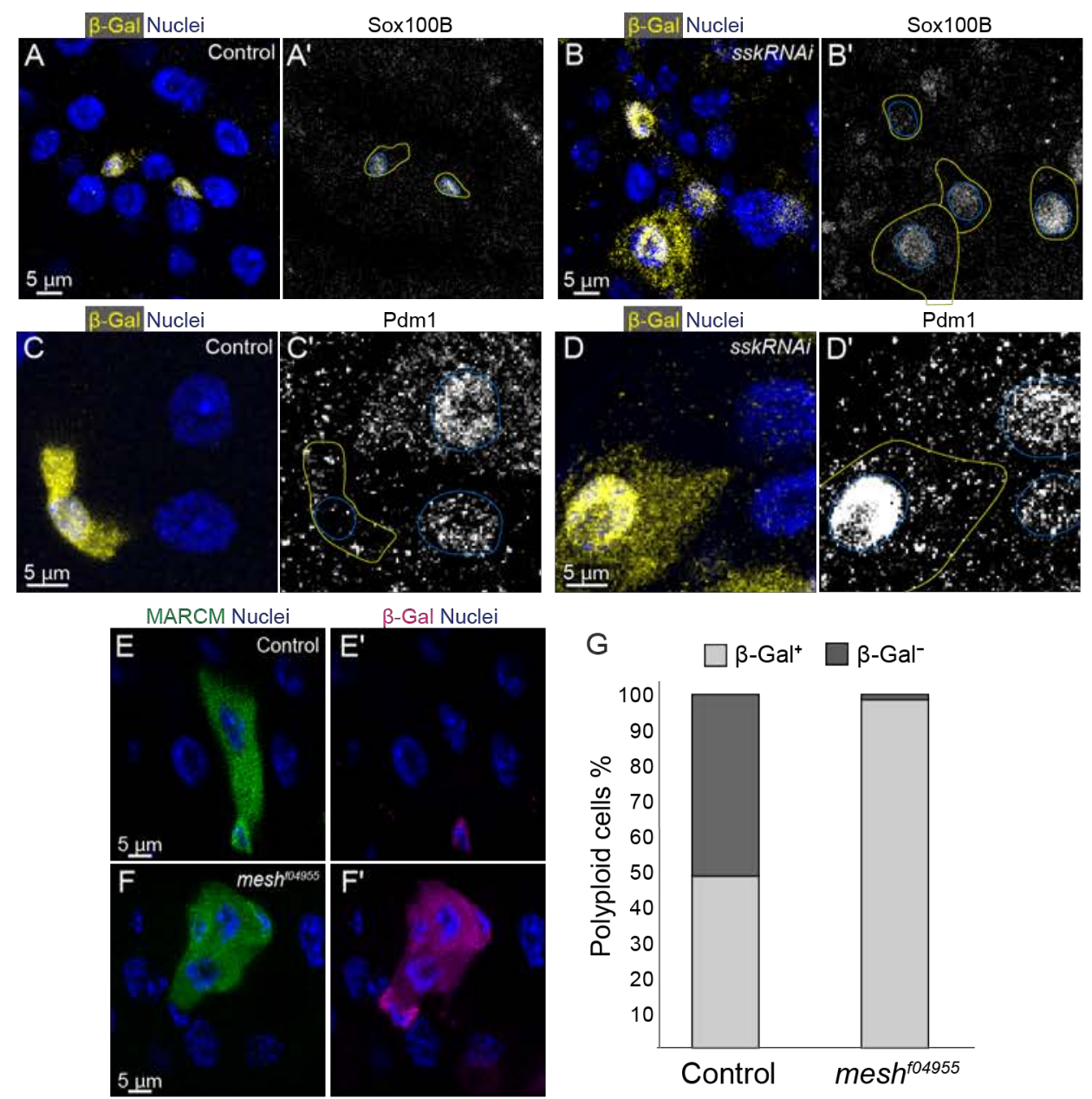

Figure S5 (Related to Figure 6). SJ-less cells exhibit an abnormal mix of enteroblast and enterocyte features.

(A-B) $S u(H)^{t s}>$ sskRNAi cells express the stem cell/enteroblast transcription factor Sox100B. Planar views of control $S u(H)$ cells (A) and $S u(H)^{t s}>$ sskRNAi cells. (B). Left panels: Yellow, $S u(H)$-lacZ ( $\beta$-gal immunostain); blue, nuclei (DAPI). Right panels: Sox100B immunostain. Yellow and blue outlines in right panels indicate $S u(H)-l a c Z^{+}$cells and their nuclei, respectively.

(C-D) $\mathrm{Su}(H)^{t_{s}}>$ sskRNAi cells express the enterocyte-specific transcription factor Pdm1. Control $S u(H)$ cells $(C)$ and $S u(H)^{t s}>$ sskRNAi cells are shown. Left panels: Yellow, $\mathrm{Su}(\mathrm{H})$-lacZ $(\beta$-gal immunostain); blue, nuclei (DAPI). Right panels: Pdm1 immunostain. Yellow and blue outlines in right panels indicate $S u(H)-l a c Z^{+}$cells and their nuclei, respectively.

(E-G) Su(H)-lacZ expression in stem cell (MARCM) clones that are either control (E) or meshnull (mesh $\left.{ }^{f 04955}\right)(\mathrm{E}) .4$-day clones are labelled with GFP (green). $\beta$-gal immunostain (red) identifies $\mathrm{Su}(H)$-lacZ-expressing cells. Nuclei are stained with DAPI (blue). In control clones, $52 \%$ of polyploid cells have lost $\beta$-Gal staining ( $\mathrm{n}=39$ polyploid cells from 133 clones, $\mathrm{N}=3$ midguts), implying that terminal differentiation of polyploid cells to enterocyte fate is complete. In mesh-null clones, only $1.1 \%$ of cells has lost $\beta$-gal staining, implying that nearly all cells, despite being polyploid, have not completed terminal differentiation ( $\mathrm{n}=89$ polyploid cells from 149 clones, $\mathrm{N}=3$ midguts). All scale bars, $5 \mu \mathrm{m}$. Full genotypes in Table 1 . 


\section{Figure 7}
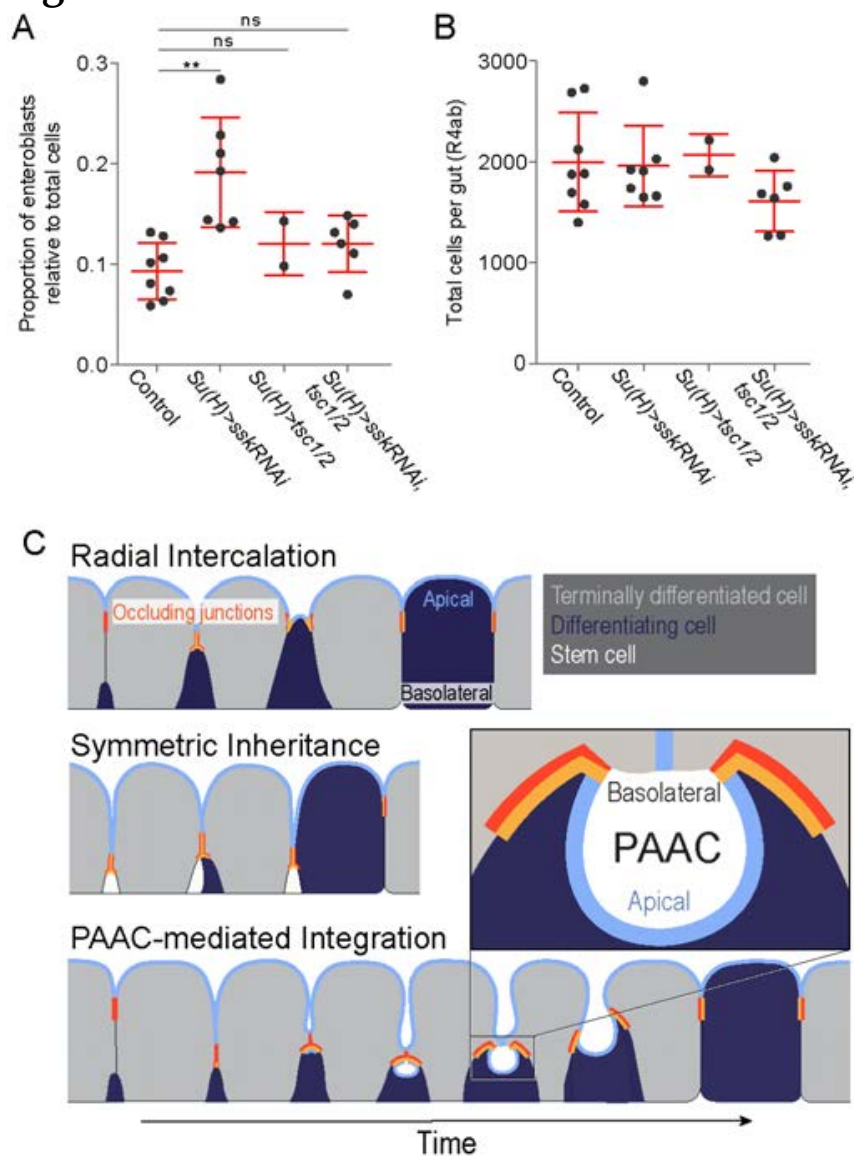

Figure 7. Impact of blocked midgut cell integration on organ-scale cell equilibrium.

(A) Proportion of $\mathrm{Su}(\mathrm{H})^{+}$cells in midguts with blocked cell integration. Plots show the percentage of $S u(H)-l a c Z^{+}$cells relative to total cells in the R4ab region of midguts with the indicated genotypes. Cell integration was blocked by inhibiting either new SJ formation $\left(S u(H)^{t s}>s s k R N A i\right)$, cell growth $\left(S u(H)^{t_{s}}>t s c 1 / 2\right)$, or both $\left(S u(H)^{t_{s}}>s s k R N A i, t s c 1 / 2\right)$ between days 4-8 of adult life. Each data point represents one midgut. Red lines show Means \pm S.D for each condition: $S u(H)$ control $0.09 \pm 0.03$ cells; $S u(H)^{t_{s}}>$ sskRNAi $-0.19 \pm 0.05 ; S u(H)^{t_{s}}>t s c 1 / 2-0.12 \pm 0.032$ cells; $S u(H)^{t_{s}}>$ sskRNAi, tsc1/2 $-0.12 \pm 0.028$ cells.

(B) Total numbers of midgut cells remain constant when cell integration is blocked. Plots show total counts of DAPI-labeled nuclei in the R4ab regions of midguts analyzed in Panel A. Each data point represents one midgut. Red lines show Means + / S.D for each condition: $S u(H)$ control $1997 \pm 489$ cells; $S u(H)^{t_{s}}>$ sskRNAi $-1960 \pm 398 ; S u(H)^{t_{s}}>t_{s c} 1 / 2-2067 \pm 210$ cells; Su $(H)^{t_{s}}>$ sskRNAi, tsc1/2 - $1611 \pm 299$ cells.

(C) Three mechanisms to incorporate stem cell progeny into a mature epithelium. Only PAAC-mediated integration enables the differentiating cell to form new barrier structures (apical plasma membrane and occluding junctions) while still sheltered by the mature occluding junction barrier. 


\section{TABLE 1 - Genotypes in Figure Panels}

\begin{tabular}{|c|c|}
\hline FIGURE & GENOTYPE \\
\hline Fig $1 \mathrm{~A}$ & MduA142GFP/Su(H)-lacZ (X Chr) \\
\hline Fig $1 \mathrm{~B}-\mathrm{H}$ & esg-Gal4, UAS-His2b::CFP; Su(H)-GFP::n/s \\
\hline Fig 2 & esg-Gal4, UAS-His2b::CFP; Su(H)-GFP::nls, ubiP-His2av::mRFP \\
\hline Fig $3 \mathrm{~A}$ & Su(H)-lacZ/ +; +; ubiP-His2AV::mRFP, Sqh-Moesin::GFP/+ \\
\hline \multirow{2}{*}{ Fig 3 B } & MduA142GFP/Su(H)-lacZ (X Chr) \\
\hline & MduA142GFP/+; Su(H)-Gal4/ +; Su(H)-lacZ, tubP-Gal80ts/+ \\
\hline Fig $3 \mathrm{C}$ & Su(H)-lacZ/ +; +; ubiP-His2AV::mRFP, Sqh-Moesin::GFP/+ \\
\hline Fig 4 B-D & UAS-Tsp2aGFP/+; Su(H)-mCherry/5966GS-Gal4; + \\
\hline Fig $4 \mathrm{E}$ & ubiP-His2Av::mRFP, sqhP-Moe::GFP \\
\hline Fig 5 & esg-Gal4, UAS-His2b::CFP; Su(H)-GFP::nls, ubiP-His2av::mRFP \\
\hline Fig $6 \mathrm{~A}$ & Su(H)-Gal4, UAS-mCD8::GFP/+; Su(H)-lacZ, tubP-Gal80ts/+ \\
\hline Fig 6 B & Su(H)-Gal4, UAS-mCD8::GFP/UAS-sskRNAi; Su(H)-lacZ, tubP-Gal80ts/+ \\
\hline Fig $6 \mathrm{C}$ & Same as Fig 6 A\&B \\
\hline Fig $6 \mathrm{D}$ & Su(H)-Gal4, UAS-mCD8::GFP/+; Su(H)-lacZ, tubP-Gal80ts/ + \\
\hline Fig $6 \mathrm{E}$ & Su(H)-Gal4, UAS-mCD8::GFP/UAS-sskRNAi; Su(H)-lacZ, tubP-Gal80ts/+ \\
\hline Fig $6 \mathrm{~F}$ & Su(H)-Gal4, UAS-mCD8::GFP/+; Su(H)-lacZ, tubP-Gal80ts/UAS-Tsc1/2 \\
\hline Fig $6 \mathrm{G}$ & Su(H)-Gal4, UAS-mCD8::GFP/UAS-sskRNAi; Su(H)-lacZ, tubP-Gal80ts/ UAS-Tsc1/2 \\
\hline \multirow[t]{2}{*}{ Fig $6 \mathrm{H}$} & Ctrl: esg-Gal4, UAS-His2b::CFP; Su(H)-GFP::nls \\
\hline & Su(H)> tsc1/2: Su(H)-Gal4, UAS-mCD8::GFP/ +; Su(H)-lacZ, tubP-Gal80ts/UAS-Tsc1/2 \\
\hline Fig 6 I & Su(H)-Gal4, UAS-mCD8::GFP/ +; Su(H)-lacZ, tubP-Gal80ts/UAS-Tsc1/2 \\
\hline Fig $6 \mathrm{~J}$ & Su(H)-Gal4, UAS-mCD8::GFP/ +; Su(H)-lacZ, tubP-Gal80ts/UAS-Tsc1/2 \\
\hline \multirow[t]{4}{*}{ Fig $7 \mathrm{~A}$} & Ctrl: Su(H)-Gal4, UAS-mCD8::GFP/ +; Su(H)-lacZ, tubP-Gal80ts/+ \\
\hline & Su(H)> sskRNAi: Su(H)-Gal4, UAS-mCD8::GFP/ UAS-sskRNAi; Su(H)-lacZ, tubP-Gal80ts/ + \\
\hline & Su(H)> tsc1/2: Su(H)-Gal4, UAS-mCD8::GFP/ +; Su(H)-lacZ, tubP-Gal80ts/UAS-Tsc1/2 \\
\hline & Su(H)> tsc1/2, sskRNAi: Su(H)-Gal4, UAS-sskRNAi/ +; Su(H)-lacZ, tubP-Gal80ts/UAS-Tsc1/2 \\
\hline Fig 7 B & Same as Fig $7 \mathrm{~A}$ \\
\hline Fig $7 \mathrm{C}$ & Same as Fig $7 \mathrm{~A}$ \\
\hline Fig S1 & esg-Gal4, UAS-His2b::CFP; Su(H)-GFP::nls, ubiP-His2av::mRFP \\
\hline Fig S2 B\&C & MduA142GFP (X Chr) \\
\hline Fig S3 & Su(H)-lacZ/+; +; ubiP-His2AV::mRFP, Sqh-Moe::GFP/+ \\
\hline Fig S4 & esg-Gal4, UAS-His2b::CFP; Su(H)-GFP::nls, ubiP-His2av::mRFP \\
\hline Fig S5 A & Su(H)-Gal4, UAS-mCD8::GFP/+; Su(H)-lacZ, tubP-Gal80ts/+ \\
\hline Fig S5 B & Su(H)-Gal4, UAS-mCD8::GFP/UAS-sskRNAi; Su(H)-lacZ, tubP-Gal80ts/+ \\
\hline Fig S5 C & Su(H)-Gal4, UAS-mCD8::GFP/+; Su(H)-lacZ, tubP-Gal80ts/+ \\
\hline Fig S5 D & Su(H)-Gal4, UAS-mCD8::GFP/UAS-sskRNAi; Su(H)-lacZ, tubP-Gal80ts/+ \\
\hline Fig S5 E & w, UAS-mCD8::GFP, hsflp122/Su(H)-lacZ; tubP-Gal4/+; FRT82B/FRT82B, tubP-Gal80 \\
\hline Fig S5 F & w, UAS-mCD8::GFP, hsflp 122/Su(H)-lacZ; tubP-Gal4/+; meshf04955/FRT82B, tubP-Gal80 \\
\hline Fig S5 G & Same as Fig S5 E\&F \\
\hline
\end{tabular}


bioRxiv preprint doi: https://doi.org/10.1101/2021.09.19.457819; this version posted September $19,2021$. The copyright holder for this preprint (which was not certified by peer review) is the author/funder, who has granted bioRxiv a license to display the preprint in perpetuity. It is made available under aCC-BY-NC-ND 4.0 International license.

\section{TABLE 2 - Reagents and Resources}

\begin{tabular}{|c|c|c|}
\hline REAGENT or RESOURCE & SOURCE & IDENTIFIER \\
\hline \multicolumn{3}{|l|}{ Antibodies } \\
\hline Mouse anti-Armadillo & DSHB & N2 7A1; RRID: AB_528089 \\
\hline Mouse anti-Coracle & DSHB & C615.16; RRID: AB_1161644 \\
\hline Mouse anti- $\beta$-galactosidase & Promega & Z3781; RRID: AB_430877 \\
\hline Donkey anti-mouse Alexa Fluor 647 & Invitrogen & A-31571; RRID: AB_162542 \\
\hline Donkey anti-rabbit Alexa Fluor 555 & Invitrogen & A-31572; RRID: AB_162543 \\
\hline Goat anti-Chicken Alexa Fluor 488 & Invitrogen & A-11039; RRID: AB_2534096 \\
\hline Goat anti-Rabbit Alexa Fluor 405 & Thermo Fisher & RRID: AB_221605 \\
\hline $\begin{array}{l}\text { GFP Polyclonal Antibody, Alexa Fluor } \\
488\end{array}$ & Thermo Fisher & A-21311; RRID: AB_221477 \\
\hline Goat anti-Mouse Alexa Fluor 405 & Thermo Fisher & A-31553; RRID: AB_221604 \\
\hline Goat anti-Mouse Alexa Fluor 647 & Thermo Fisher & A-21240; RRID: AB_2535809 \\
\hline Goat anti-Mouse Alexa Fluor 555 & Thermo Fisher & A-21137; RRID: AB_2535776 \\
\hline Goat anti-Rabbit Alexa Fluor 647 & Thermo Fisher & A-21244; RRID: AB_2535812 \\
\hline Rabbit anti-Phospho4EBP1 & Cell Signaling Technology & RRID: AB_560835 \\
\hline Rabbit anti-Pdm1 & Yang lab & N/A -- \\
\hline Rabbit anti-Snakeskin & Furuse lab & N/A \\
\hline Rabbit anti-Tetraspanin2A & Furuse lab & N/A \\
\hline Rabbit anti-Sox100B & Russell lab & N/A \\
\hline Rabbit anti-Karst & Thomas lab & N/A \\
\hline \multicolumn{3}{|c|}{ Chemicals, Peptides, and Recombinant Proteins } \\
\hline Rhodamine Phalloidin & Invitrogen & R415; CAS Number 219920-04-4 \\
\hline RU486 & Sigma-Aldrich & $\begin{array}{l}\text { M8046-100MG; CAS Number 84371-65- } \\
3\end{array}$ \\
\hline DAPI & Thermo Fisher & RRID: AB_2629482 \\
\hline Prolong Gold antifade & Thermo Fisher & P10144 \\
\hline Isradipine & Millipore Sigma & I6658; CAS Number 75695-93-1 \\
\hline \multicolumn{3}{|l|}{ Experimental Models: Organisms/Strains } \\
\hline Drosophila: mesh ${ }^{\text {f04955 }}$ & BDSC & 18826; FLYB: FBti0042412 \\
\hline Drosophila: SqhP-Moesin::GFP & BDSC & 59023; FLYB: FBti0016051 \\
\hline Drosophila: Su(H)-Gal4 & BDSC & 93377; FLYB: FBti0204714 \\
\hline Drosophila: ubiP-His2av::mRFP & BDSC & $\begin{array}{l}\text { FLYB: FBti0077846; RRID: BDSC } \\
23650\end{array}$ \\
\hline Drosophila: $\mathrm{Su}(\mathrm{H})-\mathrm{lacZ}\left(3^{\mathrm{rd}} \mathrm{Chr}\right)$ & BDSC & 83352; FLYB: FBtp0014034 \\
\hline Drosophila: tubP-Gal80ts & BDSC & 7017; FLYB: FBti0027797 \\
\hline Drosophila: UAS-SskRNAi & VDRC & 105193; PMID: 22328496 \\
\hline Drosophila: esg-Gal4 & Kyoto DGGR & 112304; FLYB: FBti0033872 \\
\hline Drosophila: UAS-His2b::CFP & Yoshihiro Inoue lab & PMID: 24850412 \\
\hline Drosophila: FRT82B & David Bilder lab & FLYB: FBti0002074 \\
\hline Drosophila: UAS-mCD8GFP & David Bilder lab & FLYB: FBtp0002652 \\
\hline Drosophila: 5966GS-Gal4 & Henri Jasper lab & FLYB: FBti0150384 \\
\hline Drosophila: UAS-Tsc1/2 & Nicolas Tapon lab & PMID: 20573703 \\
\hline Drosophila: Su(H)-mCherry & Allison Bardin lab & N/A \\
\hline Drosophila: $\mathrm{Su}(H)-l a c Z$ (X Chr) & Sarah Siegrist lab & N/A \\
\hline Drosophila: MduA142GFP & Nicolas Buchon lab & N/A \\
\hline Drosophila: UAS-Tsp2aGFP & Norbert Perrimon lab & N/A \\
\hline Drosophila: Su(H)-GFP::nls & Joaquin de Navascués lab & PMID: 22522699 \\
\hline
\end{tabular}


bioRxiv preprint doi: https://doi.org/10.1101/2021.09.19.457819; this version posted September 19, 2021. The copyright holder for this preprint

(which was not certified by peer review) is the author/funder, who has granted bioRxiv a license to display the preprint in perpetuity. It is made available under aCC-BY-NC-ND 4.0 International license.

\begin{tabular}{|c|c|c|}
\hline REAGENT or RESOURCE & SOURCE & IDENTIFIER \\
\hline \multicolumn{3}{|l|}{ Oligonucleotides } \\
\hline $\begin{array}{l}\text { traF_U primer: CGAGAAAGAGAA- } \\
\text { TACCATGGGCGATCAA }\end{array}$ & N/A & N/A \\
\hline $\begin{array}{l}\text { traF L primer: } \\
\text { CCTGTGGTGGCACTTGCACATAGTA }\end{array}$ & N/A & $\mathrm{N} / \mathrm{A}$ \\
\hline $\begin{array}{l}\text { GFP_62U primer: CGACGTAAAC- } \\
\text { GGCCACAAGTTCA }\end{array}$ & N/A & N/A \\
\hline $\begin{array}{l}\text { GFP_495L primer: CCTCGATGTT- } \\
\text { GTGGCGGATCTTGAA }\end{array}$ & N/A & N/A \\
\hline $\begin{array}{l}\text { 3'Pout_U primer: CATA- } \\
\text { TCGCTGTCTCACTCAGACTCAA }\end{array}$ & N/A & N/A \\
\hline $\begin{array}{l}\text { Mdu3'conf_L2 primer: } \\
\text { CGCGCCACTATGTGCCGCAAA }\end{array}$ & N/A & N/A \\
\hline $\begin{array}{l}\text { Mdu3'conf_L1 primer: } \\
\text { GCCAAAAGGCATAAAAACAGCTAA }\end{array}$ & N/A & N/A \\
\hline $\begin{array}{l}\text { Mdu5'conf_U1 primer: } \\
\text { GTGTCAATGGCCCAGAGACCA }\end{array}$ & $\mathrm{N} / \mathrm{A}$ & N/A \\
\hline $\begin{array}{l}\text { Mdu5'conf_U2 primer: } \\
\text { GAAATGGGTATGAACTG- } \\
\text { CAAATCAGTA }\end{array}$ & $\mathrm{N} / \mathrm{A}$ & N/A \\
\hline $\begin{array}{l}\text { Mdu5'conf_U3 primer: } \\
\text { GAACAGGCAACAGATGCCCAGA- } \\
\text { TAATACA }\end{array}$ & N/A & N/A \\
\hline $\begin{array}{l}\text { 5'Pout_L1 primer: } \\
\text { CTTCGGTAAGCTTCGGCTATCGA }\end{array}$ & $\mathrm{N} / \mathrm{A}$ & N/A \\
\hline $\begin{array}{l}\text { 5'Pout_L2 primer: } \\
\text { CTCAACAAGCAAACGTGCACTGAA }\end{array}$ & N/A & N/A \\
\hline \multicolumn{3}{|l|}{ Software and Algorithms } \\
\hline Fiji & https://fiji.sc & RRID:SCR_002285 \\
\hline Bitplane Imaris 8 & Bitplane & RRID:SCR_007370 \\
\hline IMOD & https://bio3d.colorado.edu/imod/ & RRID:SCR_003297 \\
\hline Graphpad Prism 7 & GraphPad Software & RRID:SCR_002798 \\
\hline
\end{tabular}




\section{Moreno-Roman_Fig1}
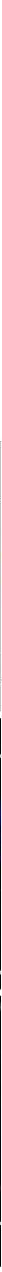

$E$
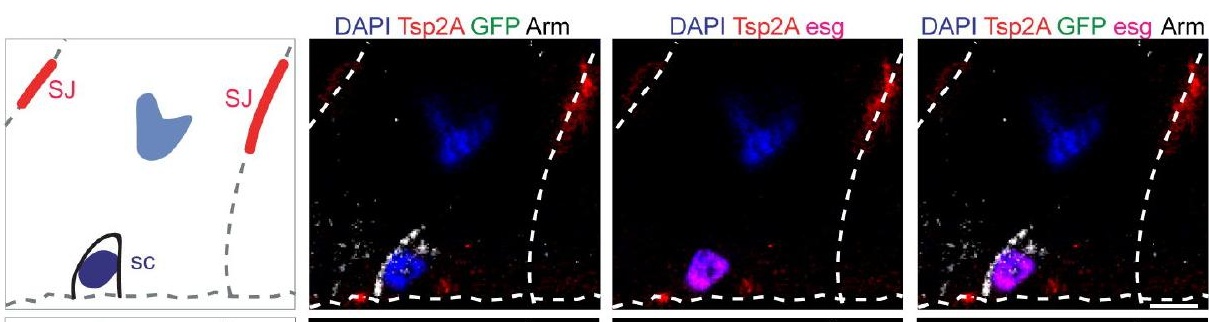

F
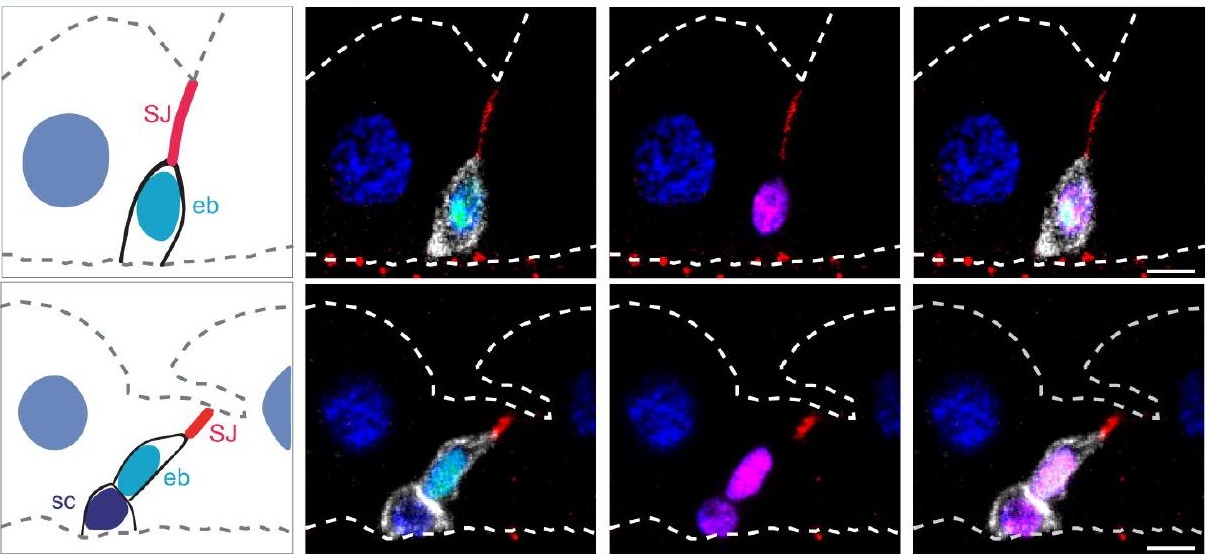


\section{Moreno-Roman_Fig2}

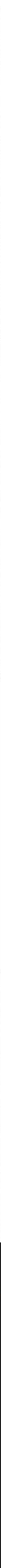


Moreno-Roman_Fig 4.
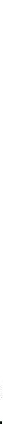

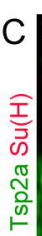

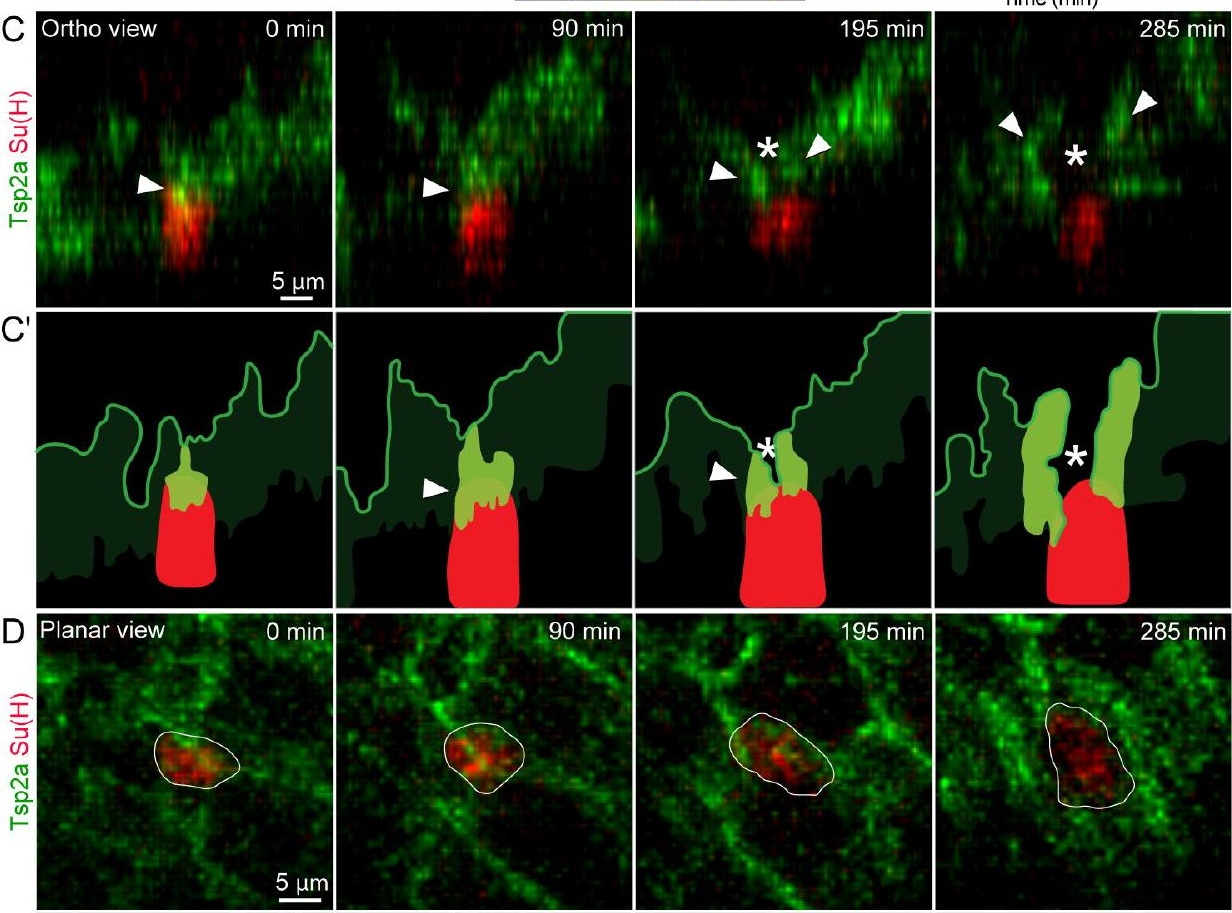

D'

Planar view

㞼

(i5)

(2)
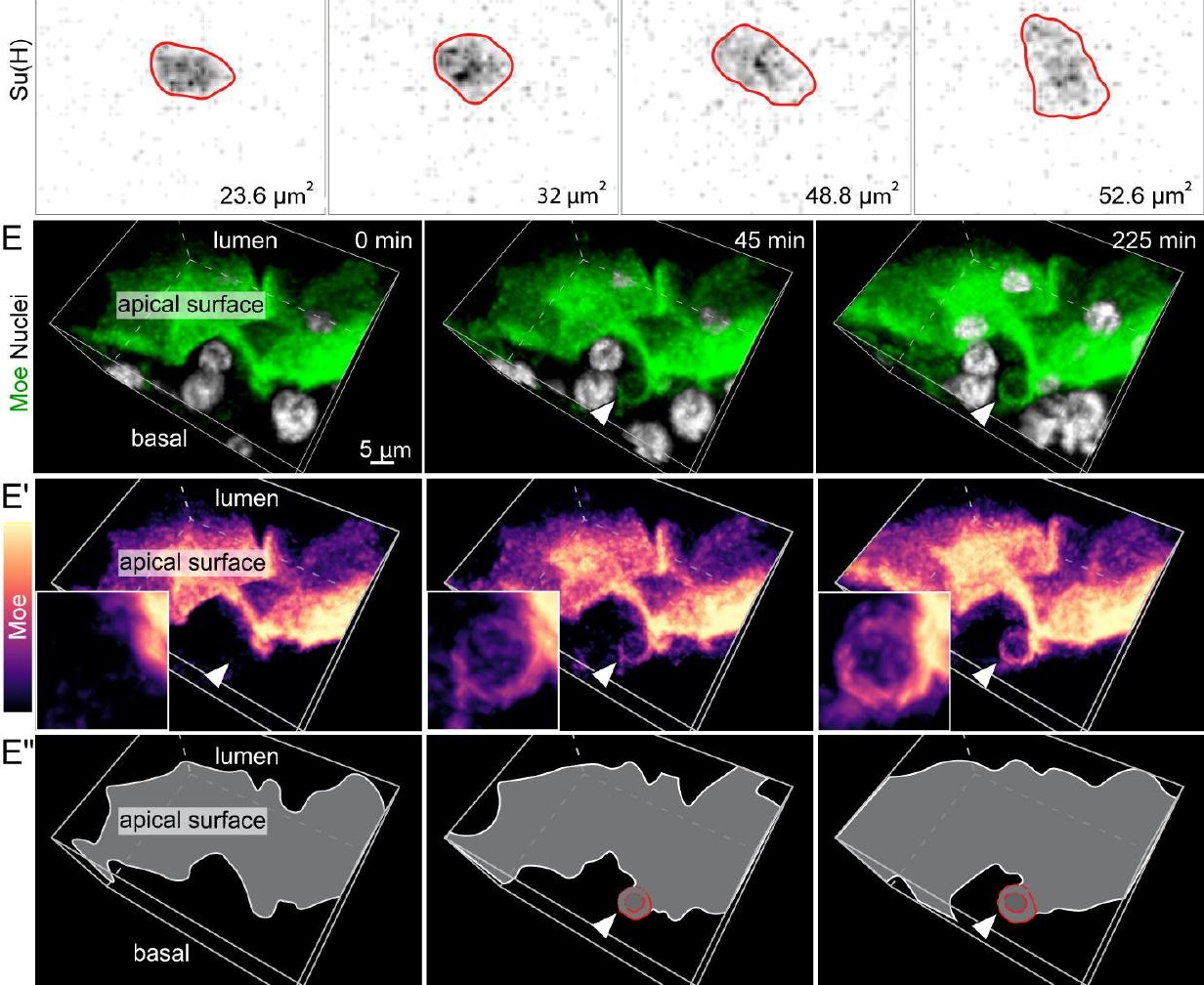

E" 
Deno-Roman_Fig 5

A

Enterocyte 1

B

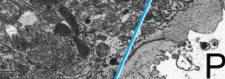

C
Enterocyte 2
Enters

$\mathrm{C}-\mathrm{s}, \mathrm{s}, \mathrm{s}, \mathrm{s}$
(2)

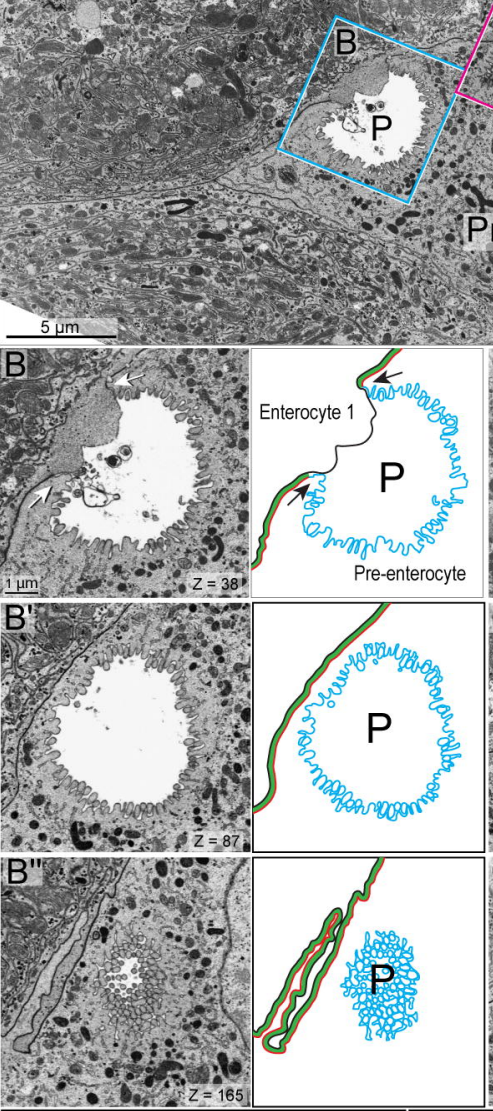

\section{A 20.5 .5}

$Z=38$
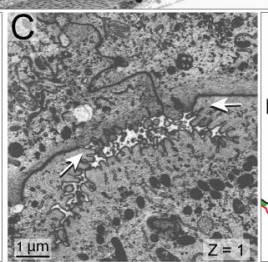

pre-P

ins

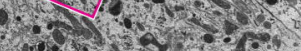

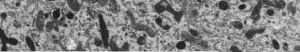

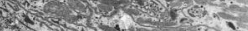

$\operatorname{lin}^{2}$

$y^{2}+0^{\circ}$

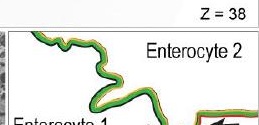

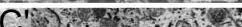

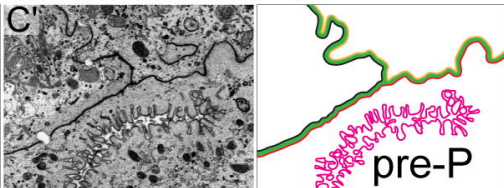

5. 31 .

Enterocyte 1 a
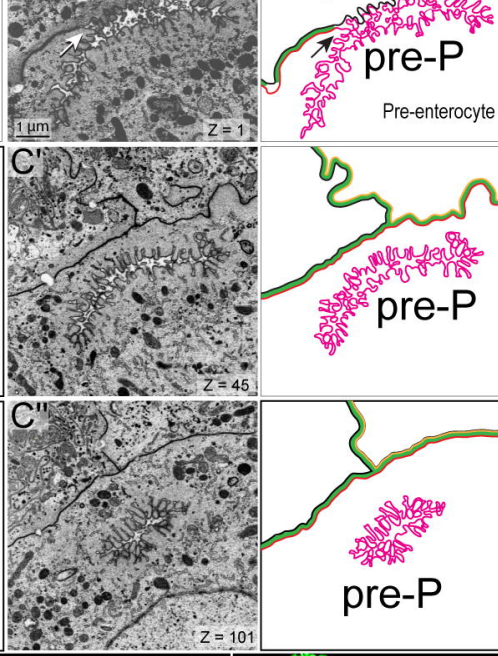

Pre-enterocyte

D
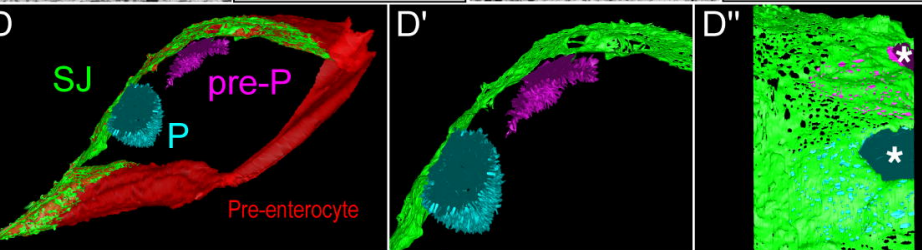
Moreno-Roman_Fig 7

A

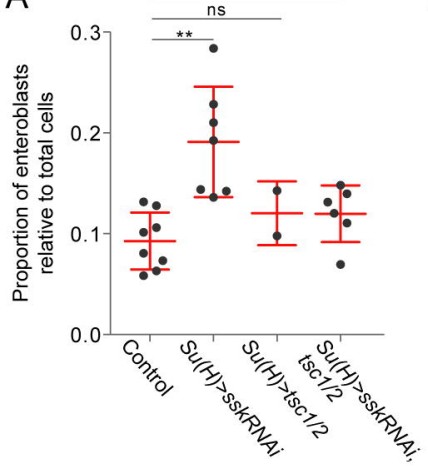

B

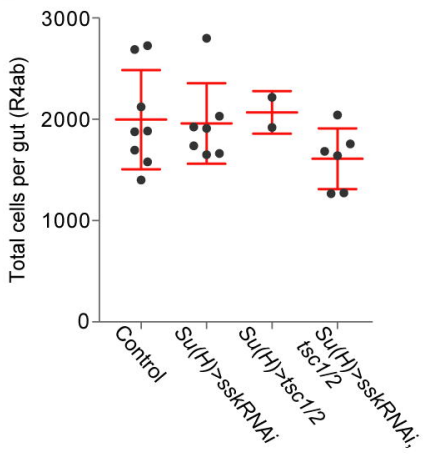

C

Radial Intercalation
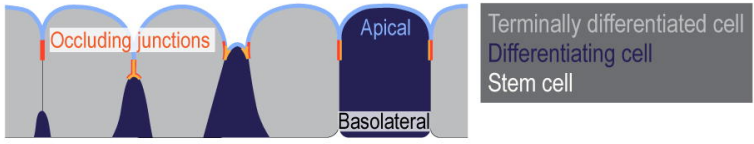

Symmetric Inheritance

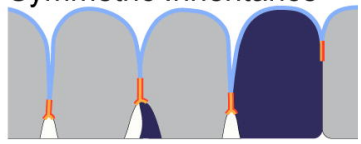

PAAC-mediated Integration
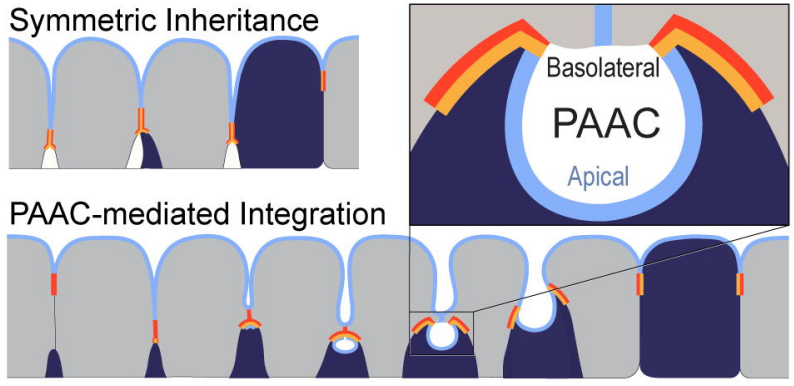